Review Article

\title{
Defects in Tendon, Ligament, and Enthesis in Response to Genetic Alterations in Key Proteoglycans and Glycoproteins: A Review
}

\author{
Subhash C. Juneja and Christian Veillette \\ Arthritis Program, Division of Orthopaedic Surgery, Toronto Western Hospital, Toronto, ON, Canada M5T 2S8 \\ Correspondence should be addressed to Subhash C. Juneja; sjuneja.phd@gmail.com
}

Received 22 May 2013; Accepted 7 August 2013

Academic Editor: Ruben Burgos-Vargas

Copyright (C) 2013 S. C. Juneja and C. Veillette. This is an open access article distributed under the Creative Commons Attribution License, which permits unrestricted use, distribution, and reproduction in any medium, provided the original work is properly cited.

\begin{abstract}
This review summarizes the genetic alterations and knockdown approaches published in the literature to assess the role of key proteoglycans and glycoproteins in the structural development, function, and repair of tendon, ligament, and enthesis. The information was collected from (i) genetically altered mice, (ii) in vitro knockdown studies, (iii) genetic variants predisposition to injury, and (iv) human genetic diseases. The genes reviewed are for small leucine-rich proteoglycans (lumican, fibromodulin, biglycan, decorin, and asporin); dermatan sulfate epimerase (Dse) that alters structure of glycosaminoglycan and hence the function of small leucine-rich proteoglycans by converting glucuronic to iduronic acid; matricellular proteins (thrombospondin 2, secreted phosphoprotein 1 (Spp1), secreted protein acidic and rich in cysteine (Sparc), periostin, and tenascin X) including human tenascin C variants; and others, such as tenomodulin, leukocyte cell derived chemotaxin 1 (chondromodulin-I, ChM-I), CD44 antigen (Cd44), lubricin (Prg4), and aggrecan degrading gene, a disintegrin-like and metallopeptidase (reprolysin type) with thrombospondin type 1 motif, 5 (Adamts5). Understanding these genes represents drug targets for disrupting pathological mechanisms that lead to tendinopathy, ligamentopathy, enthesopathy, enthesitis and tendon/ligament injury, that is, osteoarthritis and ankylosing spondylitis.
\end{abstract}

\section{Introduction}

1.1. Proteoglycans and Glycoproteins. Proteoglycans are proteins that are heavily glycosylated. The basic proteoglycan unit consists of a core protein with one or more covalently attached GAG chain(s) at specific site(s) [1]. The GAG chains comprise disaccharide units composed of aminoglycan and uronic acid (glucuronic and or iduronic acid) [2]. The chains are long, linear carbohydrate polymers that are negatively charged under physiological conditions, due to the occurrence of sulfate and uronic acid groups. Proteoglycans occur in the connective tissue. Glycoproteins, on the other hand, are proteins that contain oligosaccharide/glycans attached to polypeptide side chains covalently. The carbohydrate is attached to the protein in a cotranslational or posttranslational modification via glycosylation. Secreted extracellular proteins are often glycosylated [3]. In the proteins that have extracellular segments, those segments are also glycosylated. Glycoproteins are often important integral membrane proteins, where they play a role in cell-cell interactions.

1.2. Tendon, Ligament, and Enthesis. A tendon is a compositionally complex tissue with a predominantly mechanical function: translating muscular contractions into joint movement by transmitting forces from muscle to bone [4]. Histologically, tendons consist of dense regular connective tissue fascicles encased in dense irregular connective tissue sheaths. Tendons are composed mostly of parallel arrays of collagen fibers closely packed together (Figures 1(a), 1(b), and $2(\mathrm{~b})$ ). The dry mass of normal tendons, which makes up about $30 \%$ of the total mass with water, is composed of about $86 \%$ collagen, $2 \%$ elastin, $1 \%-5 \%$ proteoglycans, and $0.2 \%$ inorganic components such as copper, manganese, 

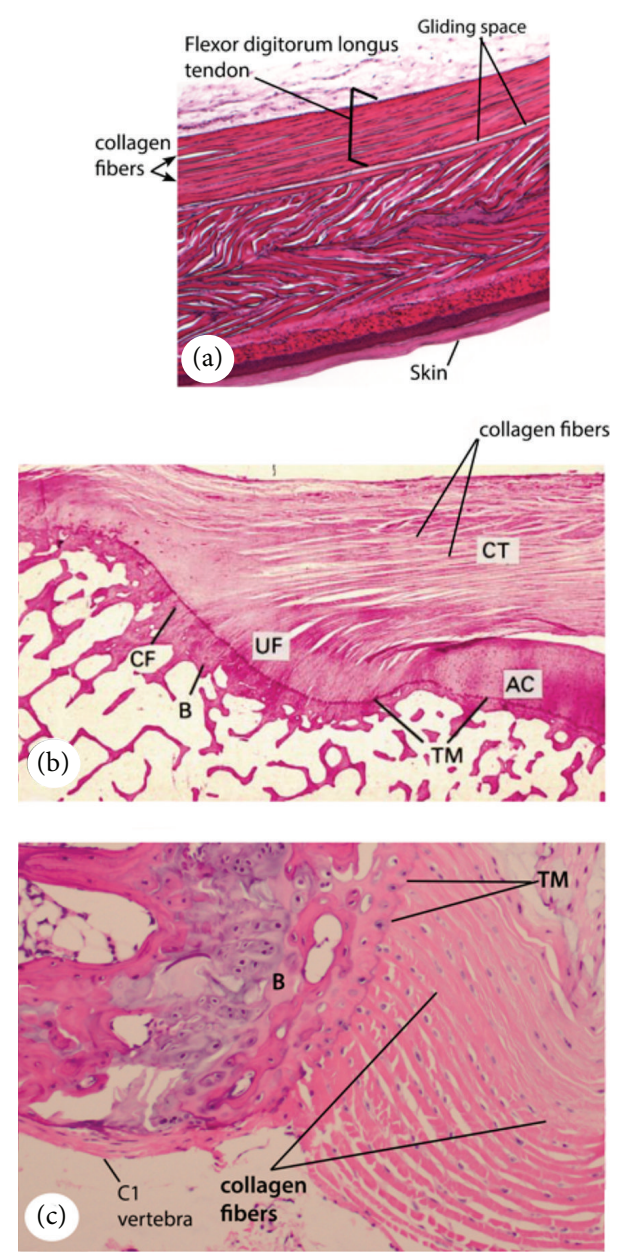

FIgURE 1: (a) Longitudinal section of FDL tendon from a 3-month old mouse. Tendon is composed of parallel collagen fibers and cells aligned (dark blue) in the direction of fibers. Gliding space is shown. (b) The normal structure of fibrocartilaginous entheses. The 4 zones of tissue at the insertion of the human supraspinatus tendon: dense fibrous connective tissue (CT), uncalcified fibrocartilage (UF), calcified fibrocartilage (CF), and bone (B). Reprinted from Benjamin and Ralphs (1998) [13], 1998, Anatomical Society of Great Britain and Ireland, with permission from John Wiley and Sons. AC, articular cartilage; TM, tidemark. (c) Annulus fibrosus fibers between tail vertebra $\mathrm{C} 1$ (shown) and C2 (not shown) from 3-month old mouse, showing entheses.

and calcium [5]. The collagen portion is made up of 97\%$98 \%$ Col I, with small amounts of other types of collagen $[5,6]$. The tenocytes produce the collagen molecules, which aggregate end-to-end and side-to-side to produce collagen fibrils. Fibril bundles are organized to form fibers with the elongated tenocytes closely packed between them. There is a three-dimensional network of cell processes associated with collagen in the tendon. The cells communicate with each other through gap junctions, and this signaling gives them the ability to detect and respond to mechanical loading [7]. A ligament is the fibrous tissue similar to tendon except that it connects bone to other bone. Periodontal ligament comprises group of fibers that attach the cementum of teeth to the surrounding alveolar bone.

Enthesis (plural, entheses) is the point at which a tendon or ligament or muscle inserts into bone, where the collagen fibers are mineralized and integrated into bone tissue. There are two types: fibrous entheses and fibrocartilaginous entheses. In a fibrous enthesis, the collagenous tendon or ligament directly attaches to the bone, whilst the fibrocartilaginous enthesis displays 4 zones during the transition from tendon/ligament to bone: (i) tendon area displaying longitudinally oriented fibroblasts and a parallel arrangement of collagen fibers, (ii) a fibrocartilaginous region of variable thickness where the structure of the cells changes to chondrocytes, (iii) an abrupt transition from cartilaginous to calcified fibrocartilage-the so-called tidemark, and (iv) bone [8].

Tendon or ligament and bone display dramatically different mechanical behavior $[9,10]$. At the hierarchical level of the tissue, tendon has a tensile modulus on the order of $200 \mathrm{MPa}$ in the direction of muscle force, but buckles in compression (i.e., it behaves like a rope) [10]. Bone, on the other hand, has a modulus of $20 \mathrm{GPa}$ in both tension and compression, and is rigid and brittle relative to tendon [9]. The attachment of a compliant material like tendon to a relatively stiff material like bone is a fundamental engineering challenge [11, 12]. Enthesis is a common region for overuse injuries. It is targeted in ankylosing spondylitis and psoriatic arthritis $[8,13]$. A few images of enthesis are shown in Figures $1(\mathrm{~b}), 1(\mathrm{c})$, and 2(c).

1.3. Genetics and Knockdown Approaches. Gene knockout mice [14], in vitro knockdown studies [15], gene overexpressing mice [15], patients with genetic disorder [16], and subjects with genetic variants linked to susceptibility to disease [17] are useful tools to better understand the gene functions and human diseases and to develop therapeutical strategies to treat the human diseases. Tendons, ligaments, and entheses are the key elements of musculoskeletal function. A number of genes for proteoglycans and glycoproteins play role in their development, structure, and function. This review summarizes the up-to-date published literature on the role of key proteoglycans and glycoproteins which affects the structural development, function, mechanical and viscoelastic properties, healing process, and calcification in tendons, ligaments and entheses at young age, adulthood, and or during aging. The information has been collected from (i) mice deleted in single or double genes, (ii) mice presenting different content of proteoglycan and collagen in tendon, (iii) knockdown studies, (iv) human patients with genetic disorder, and (v) gene variants responsible for susceptibility to tendon/ligament injury. The genes presented here are in mouse otherwise mentioned in human: (i) small leucine-rich proteoglycans: Fmod, Lum, Dcn, Bgn, and ASPN (human), (ii) matricellular: Thbs2, Spp1, Sparc, Postn, TNC (human), and Tnxb, (iii) other proteoglycans or glycoproteins: Tnmd, Lect1, TNMD (human), Cd44, Prg4, and PRG4 (human), (iv) genes affecting proteoglycan responsible in tendon/ligament function: Dse and Adamts5 and (v) other genes studied with 


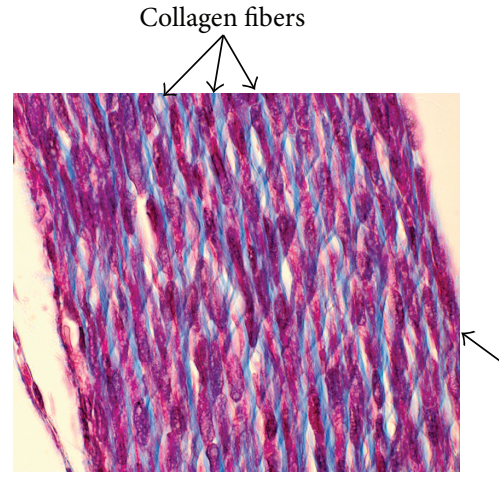

(b) $(\mathrm{e}) \nwarrow$

$\nwarrow$

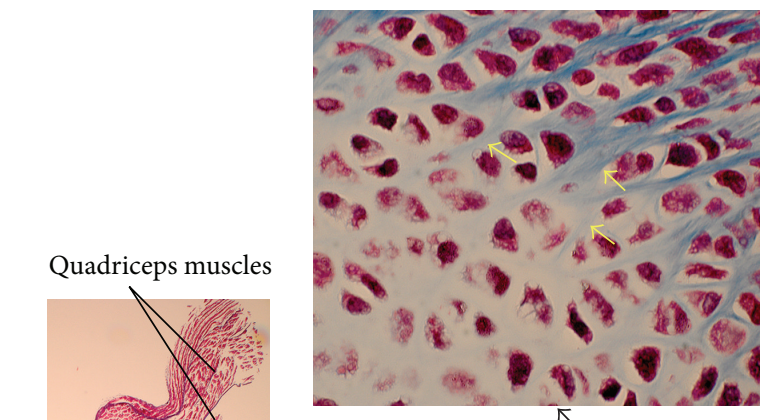

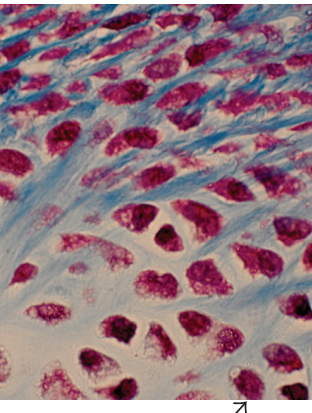

(d)

Quadriceps tendon

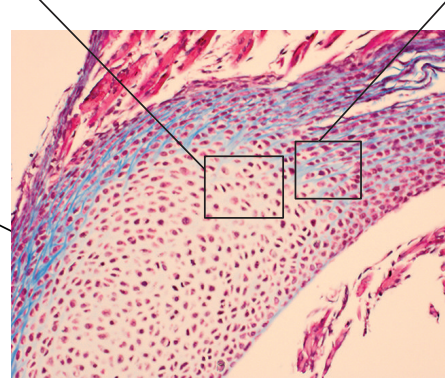

(c)

Figure 2: (a) Masson's trichrome staining of postnatal day 1 patella with patellar and quadriceps tendon in mouse at 4x. (b) Higher magnification (100x) shows patellar tendon composed of parallel collagen fibers (blue) with cells aligned almost parallel to fibers. Enthesis in rectangle (i.e., quadriceps tendon insertion on patella) is shown (a). Higher magnification of enthesis at 20x (c) and at 100x ((d) and (e)). Collagen fibers (blue) show penetration on patella (d) and ending on patella ((e), yellow arrows).

proteoglycan or glycoprotein: Colla1 ${ }^{\mathrm{mov} 13}$, Colla1 $^{\mathrm{tm} 1 \mathrm{Jae}}$, and human COL27A1 (Table 1).

\section{Small Leucine-Rich Proteoglycans (SLRPs)}

Small leucine-rich proteoglycans belong to the LRR superfamily of proteins. Members may contain up to 38 LRRs. The LRR domain is 20-29 amino acids long with asparagine and leucine residues in conserved positions [18]. The LRR is a structural motif used in the diverse molecular recognition processes. SLRP contains five-class (I-V) subfamilies (http://www.uniprot.org/uniprot): asporin, biglycan, decorin, and extracellular matrix protein 2 (class I); fibromodulin, keratocan, lumican, osteomodulin, and prolargin (class II); epiphycan, mimecan, and opticin (class III); chondroadherin, nyctalopin (class IV); podocan and podocanlike protein 1 (class V). SLRPs constitute a network of signal regulation being mostly extracellular and they are upstream of multiple signaling cascades. They affect intracellular phosphorylation, a major conduit of information for cellular responses, and modulate distinct pathways, including those driven by BMP/TGF $\beta$ superfamily members, receptor tyrosine kinases such as ErbB family members, and IGFI receptor, and Toll-like receptors [18].

2.1. Fibromodulin (Fmod) and Lumican (Lum). Fibromodulin and lumican are expressed in collagenous connective tissues and play role in establishing tissue integrity. The core protein of both has one LRRNT and 11 LRRs that are sites of proteinprotein interactions. The keratan sulfate proteoglycan Lum is a major component of the corneal stroma. It is also widely expressed in the interstitial connective tissue matrices of the skin, tendon, and intestinal submucosa [19-21]. Fibromodulin is expressed in a number of tissues including higher levels in knee epiphysis, calvarial and diaphyseal bone, nasal and costal cartilage, eye, and the bladder [19, 20, 22]. Fibromodulin has been reported to express in tendon [23]. Between the Fmod and Lum, Fmod has higher affinity for the collagen due to its two-collagen binding sites, LRR-11 (higher affinity site) and LRR-7 (lower affinity site) [24]. Lumican has one collagen-binding site homologous to Fmod LRR-7 [25]. The two SLRPs compete for collagen binding via their LRR-7 site, but Fmod has a higher affinity for collagen due to the presence of an additional higher-affinity LRR11. This relates to the physiological relevance during tendon development, when Lum is expressed early and Fmod later during the fibril assembly [26, Table I]. In addition, the abnormal collagen fibril morphology occurs early in Lumdeficient mice and late in Fmod-deficient mice [26]. Single or double mutants of these SLRPs exhibit varied range of abnormalities in collagen fibrillogenesis in Achilles, patellar, and FDL tendons indicating their requirement for tendon collagen fibrillogenesis [26-28, Table I]. Abnormalities in patellar tendon lead to OA disease in double mutants [28, Table I]. An increased content of non-cross-linked Col $\alpha 2$ (I) was found in tendon from $\mathrm{Fmod}^{-/-}$mice. Fibromodulin may specifically target the cross-linking between $\alpha 1$ (I) and 


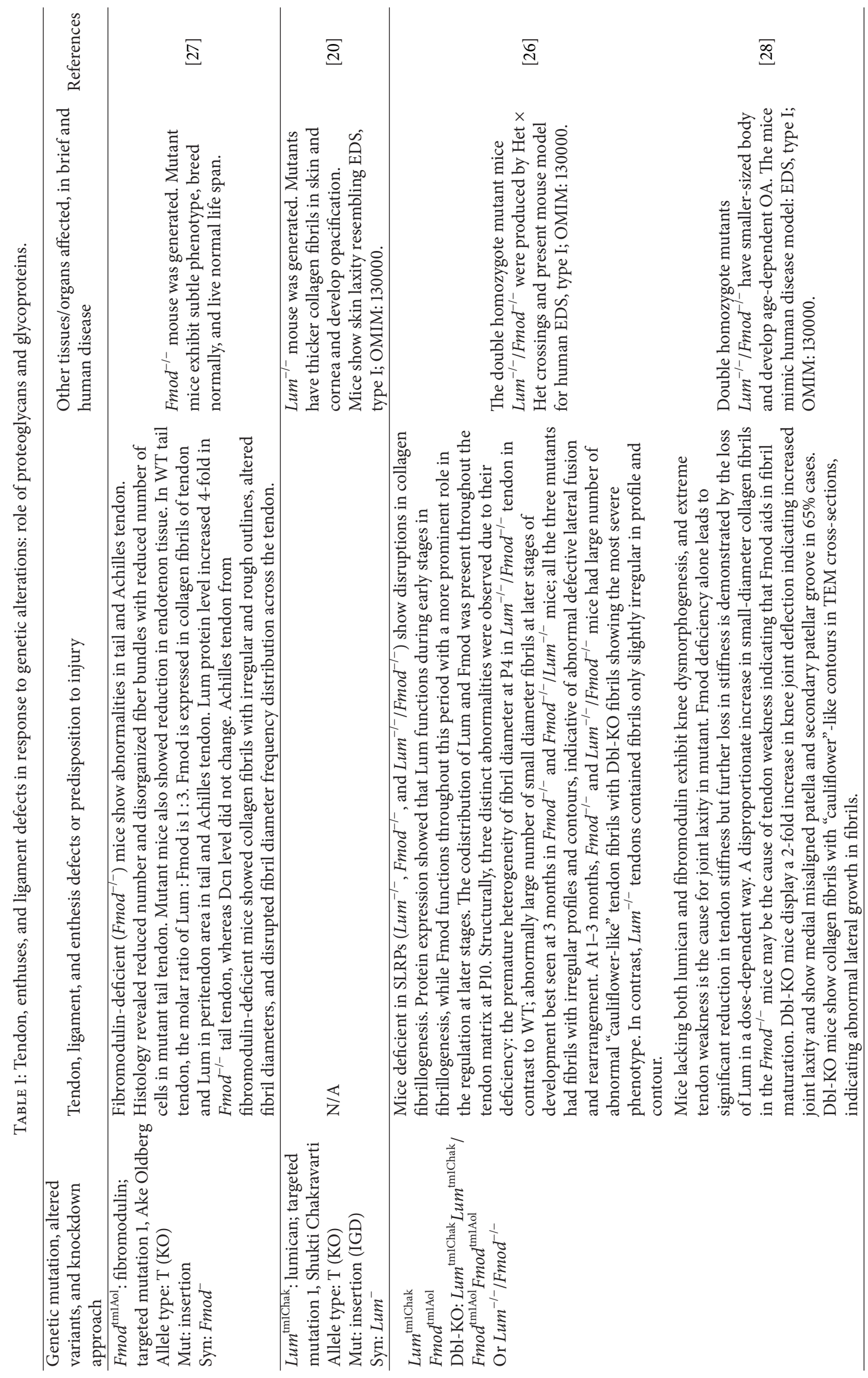




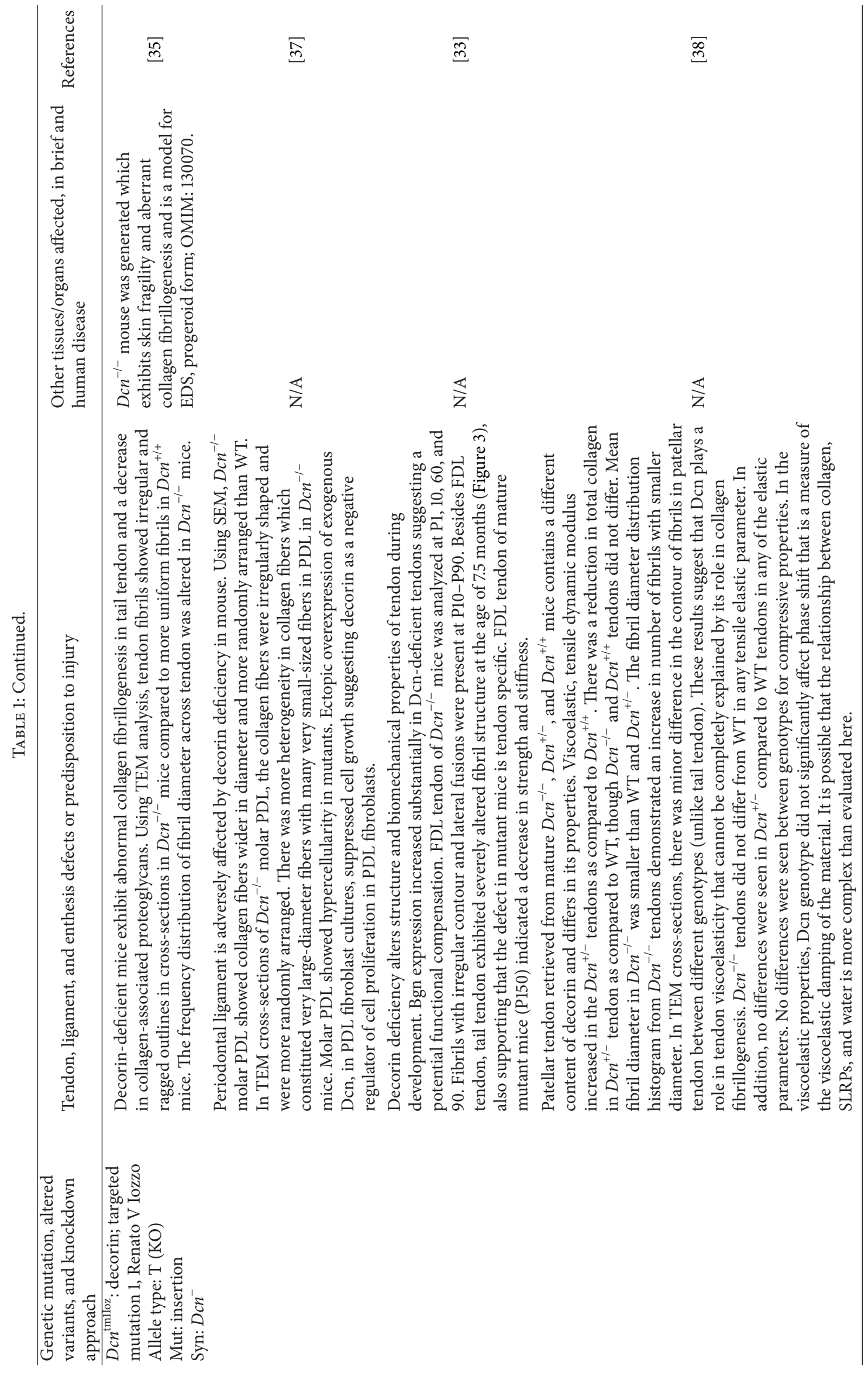




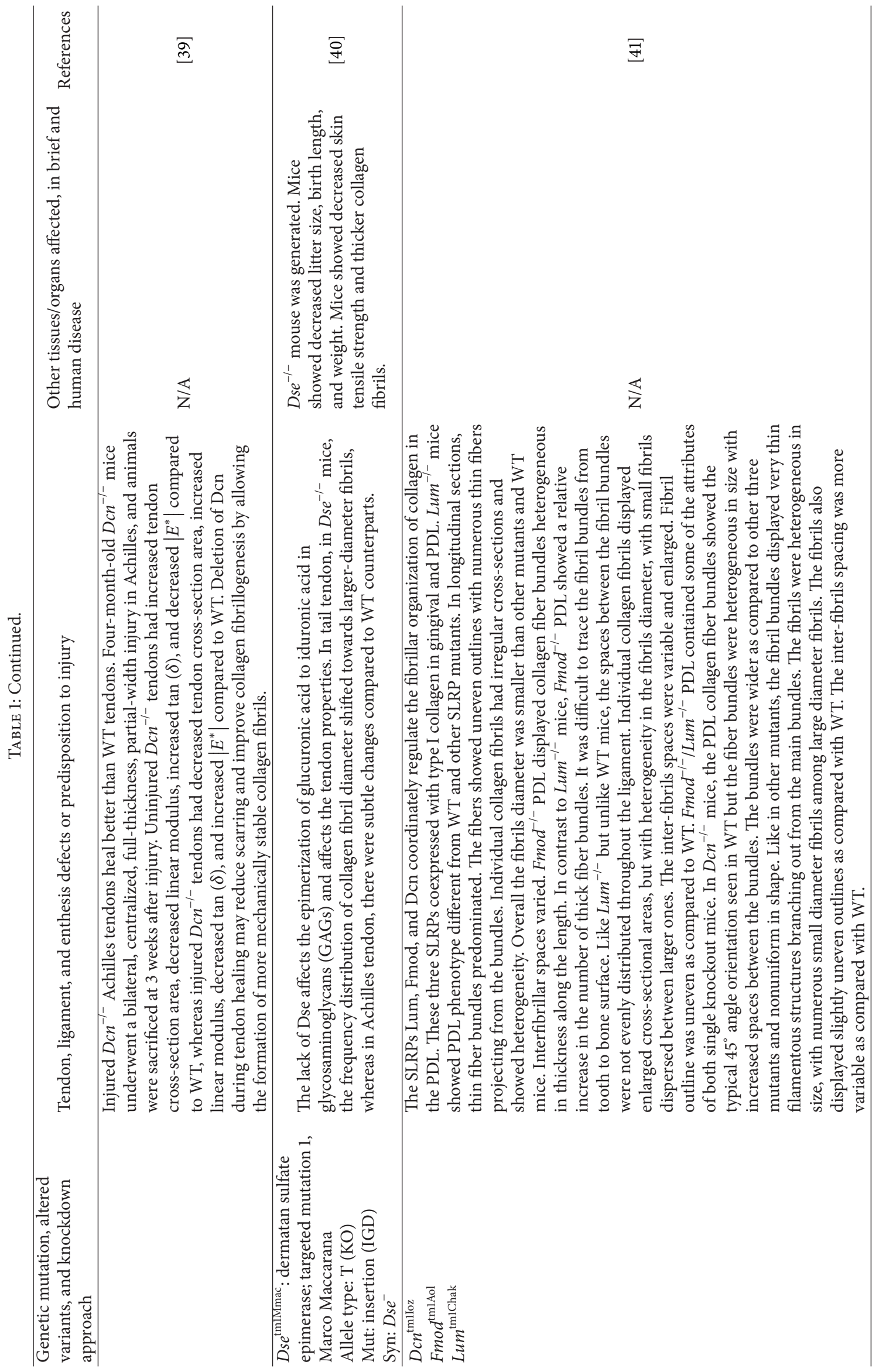




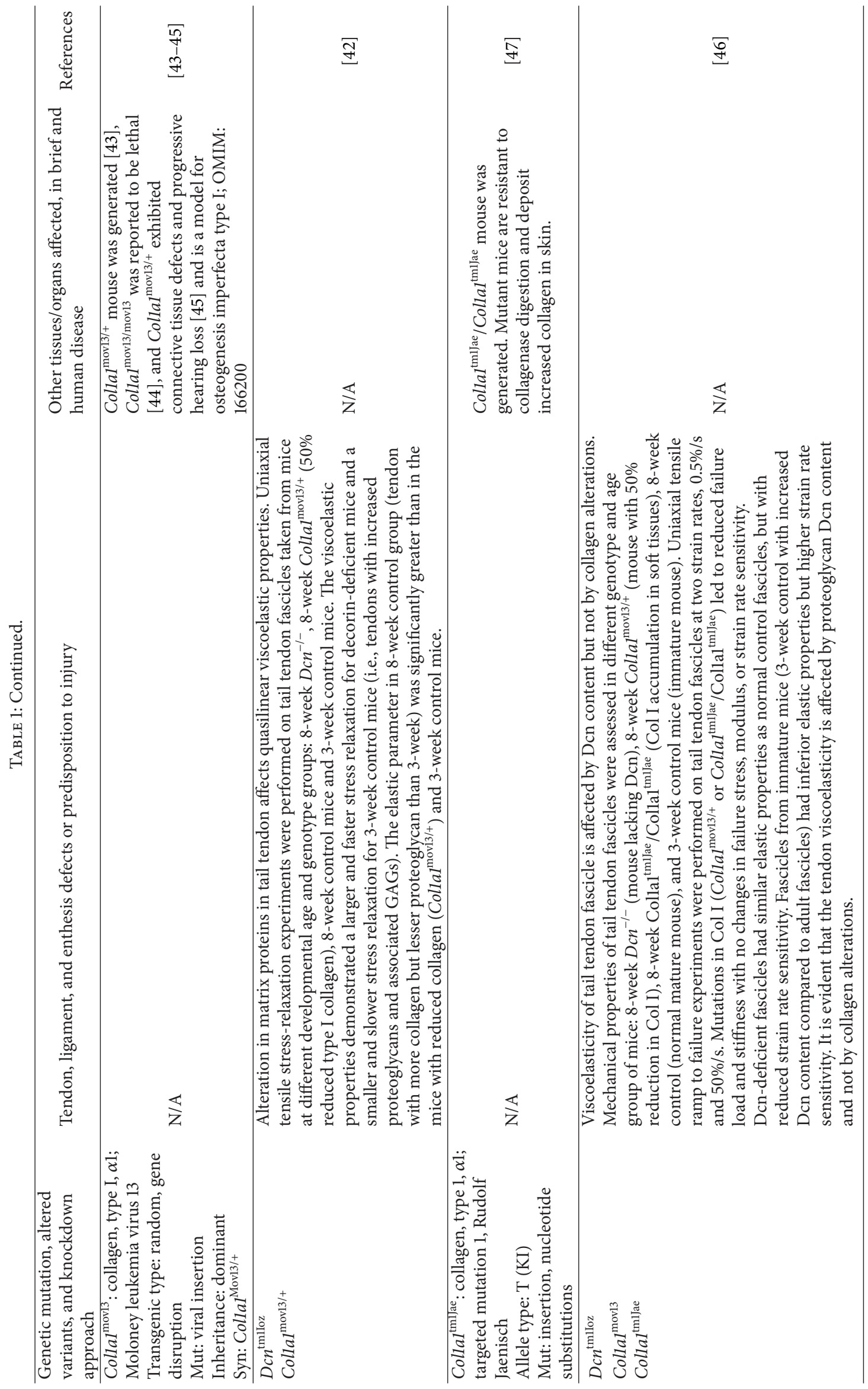




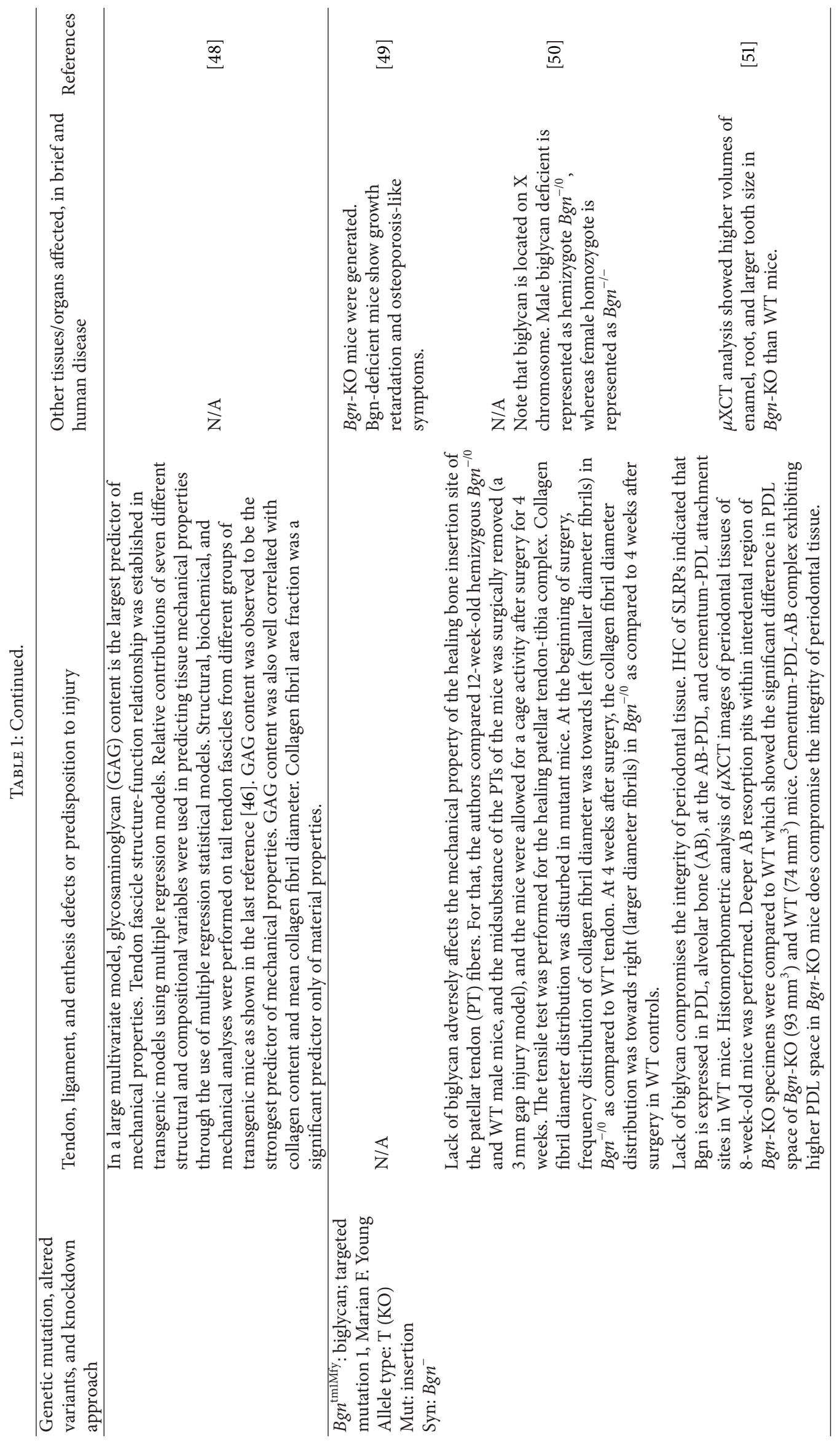




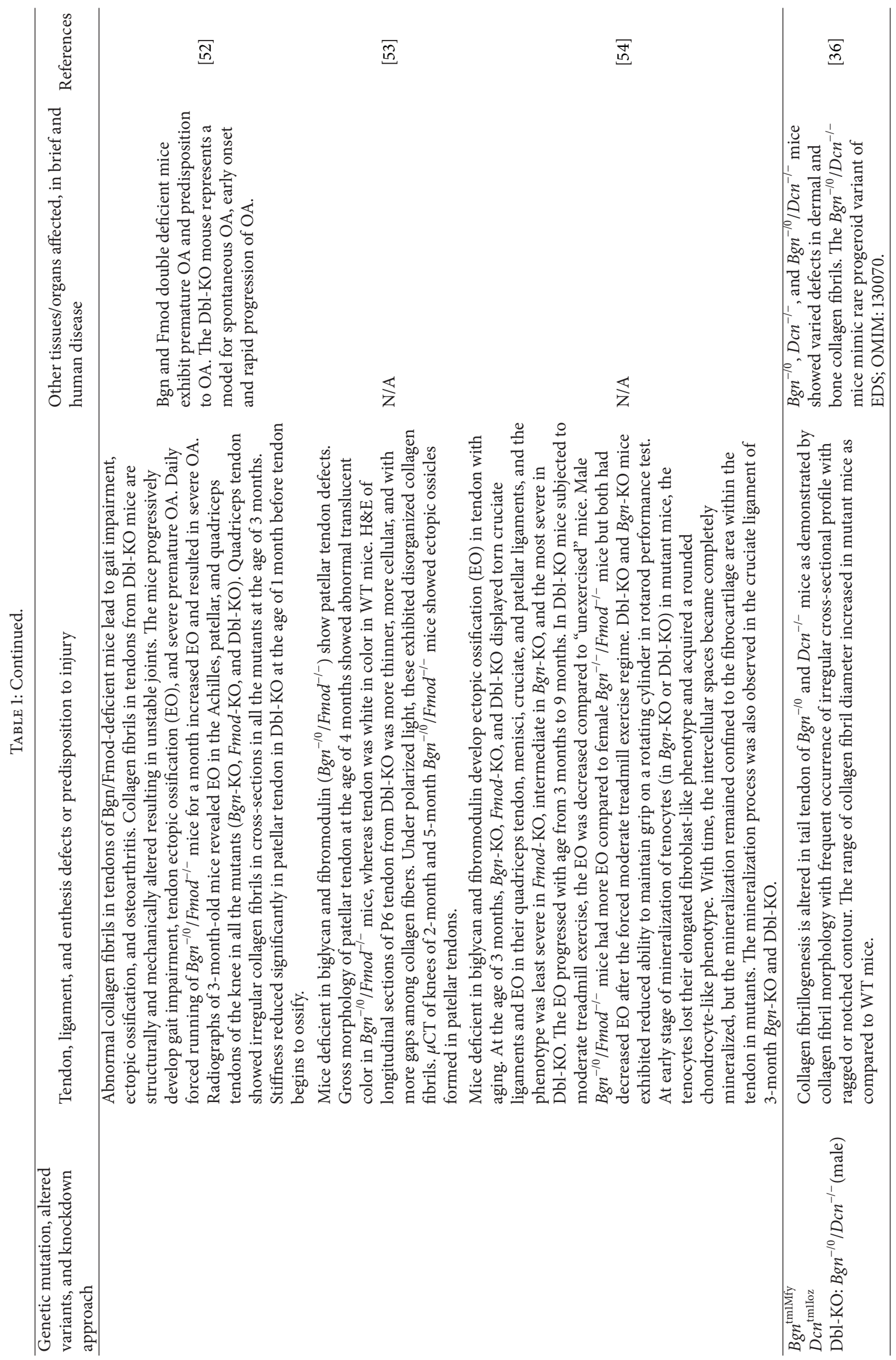




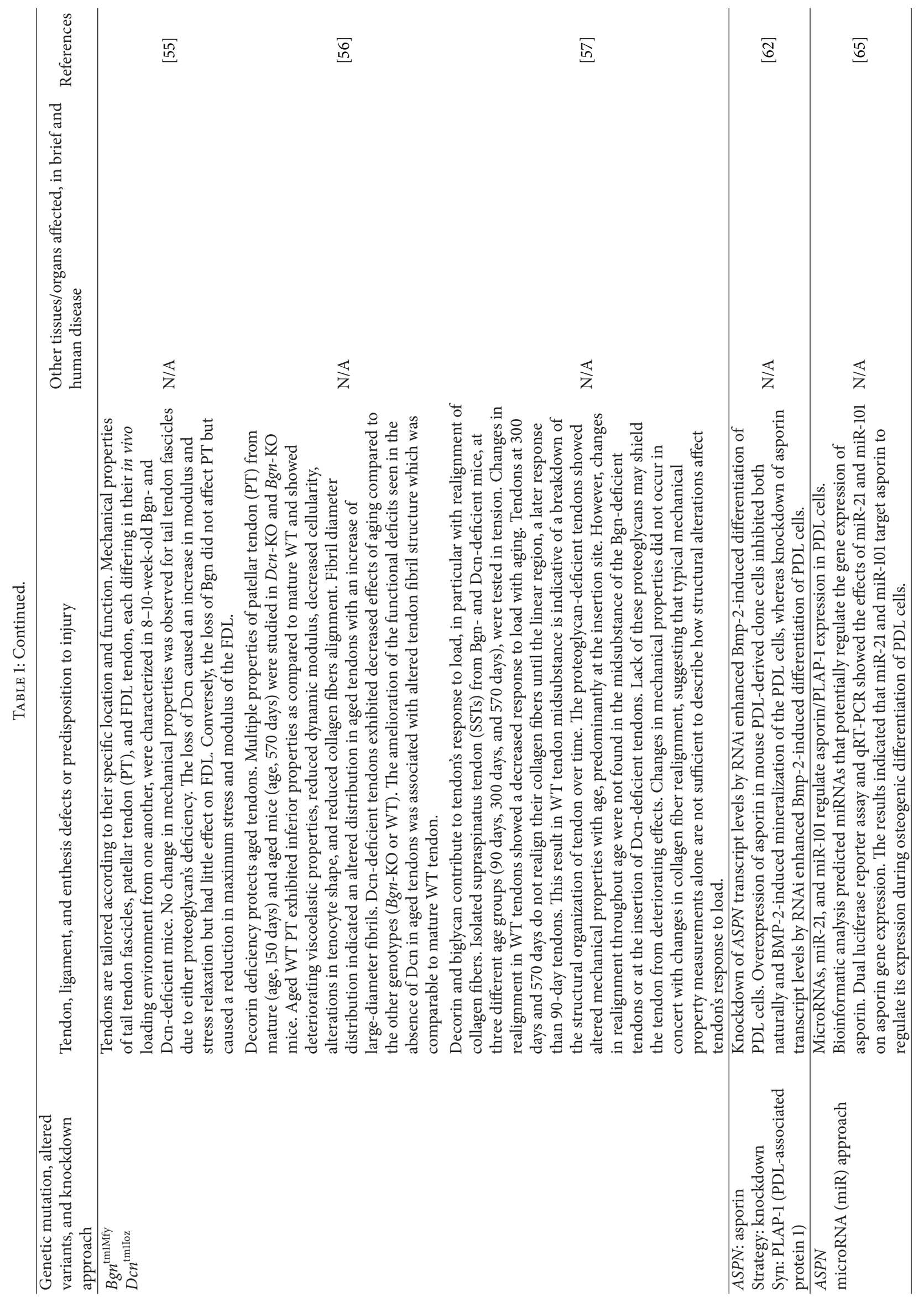




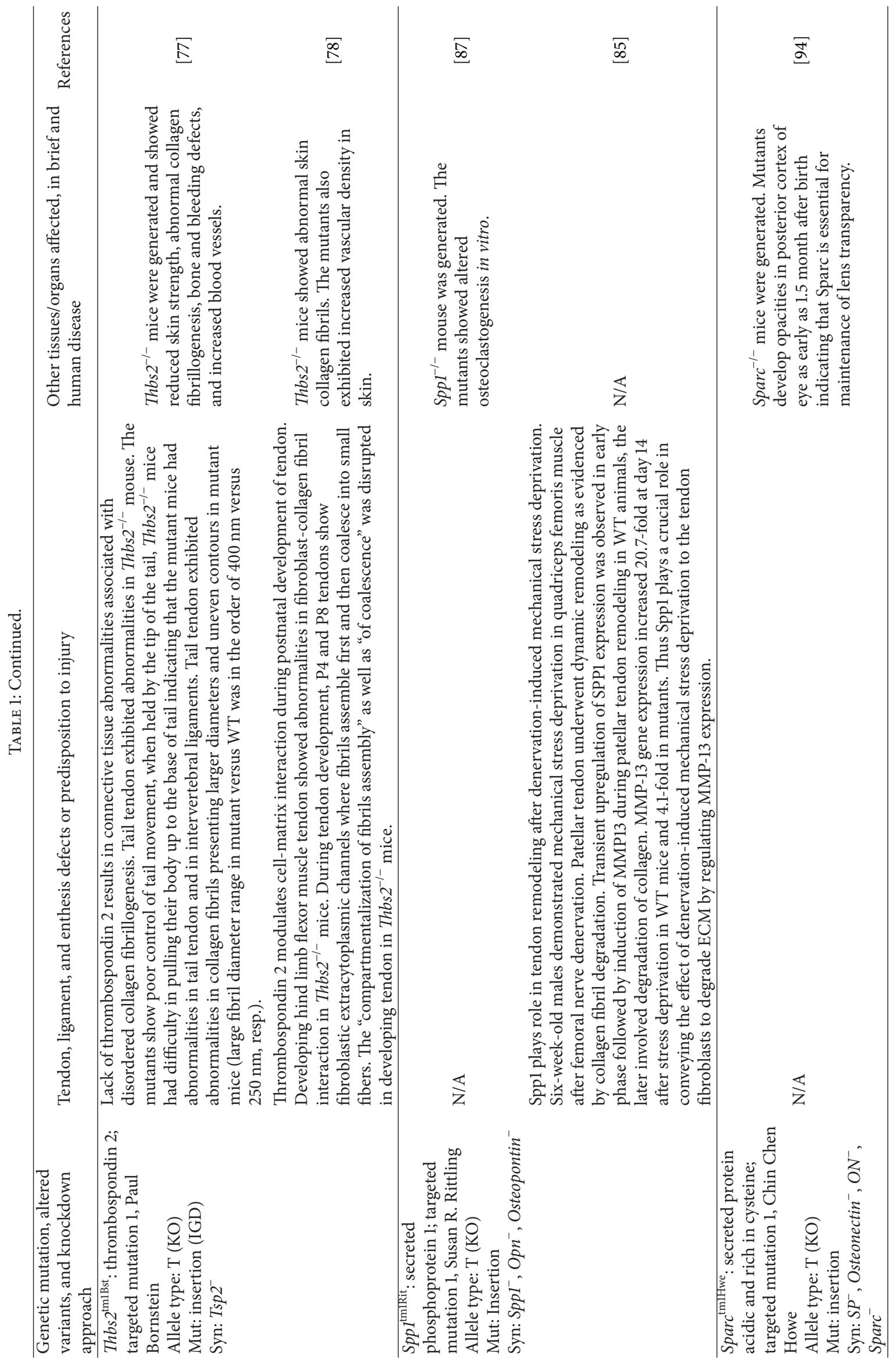




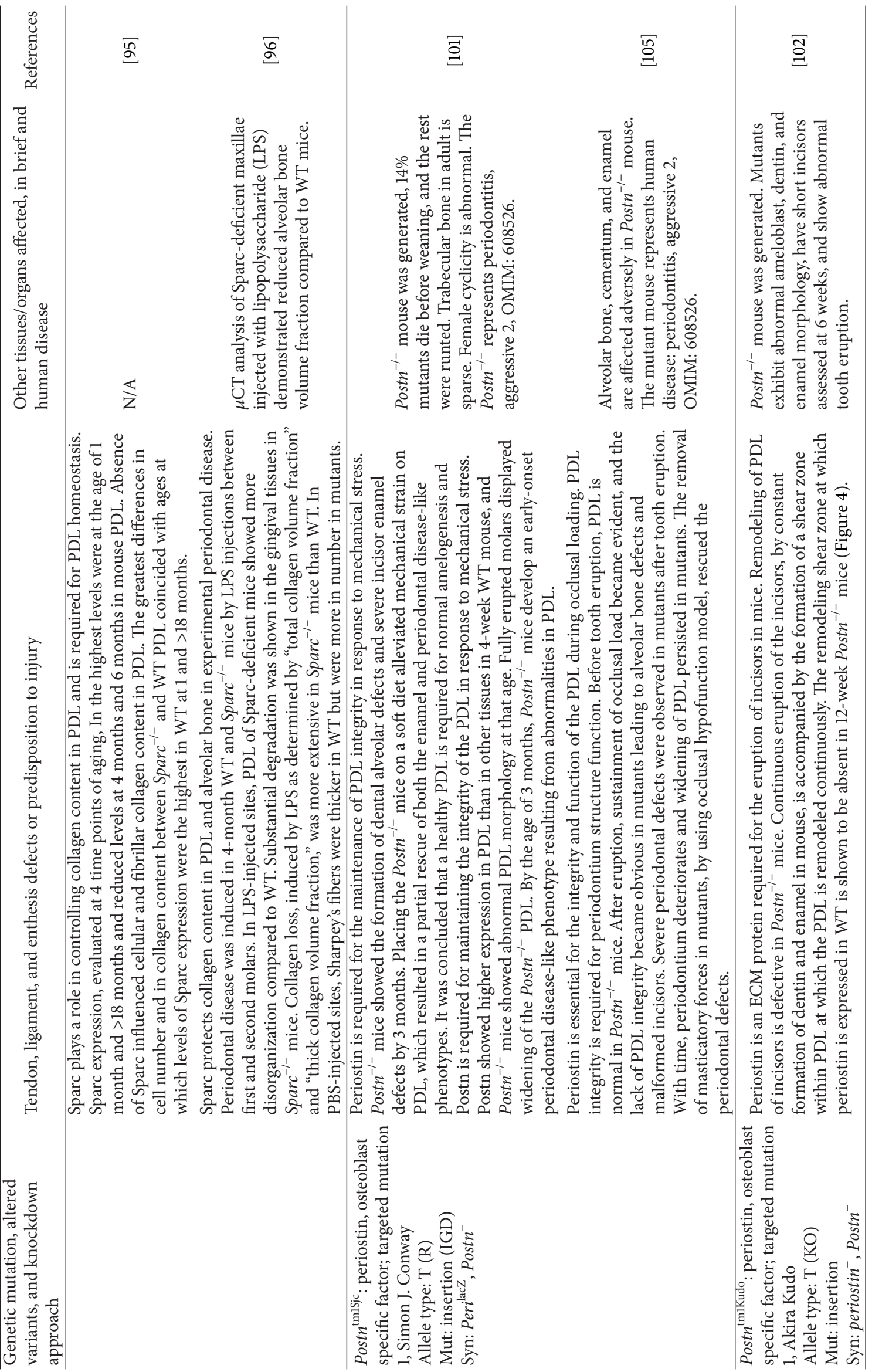




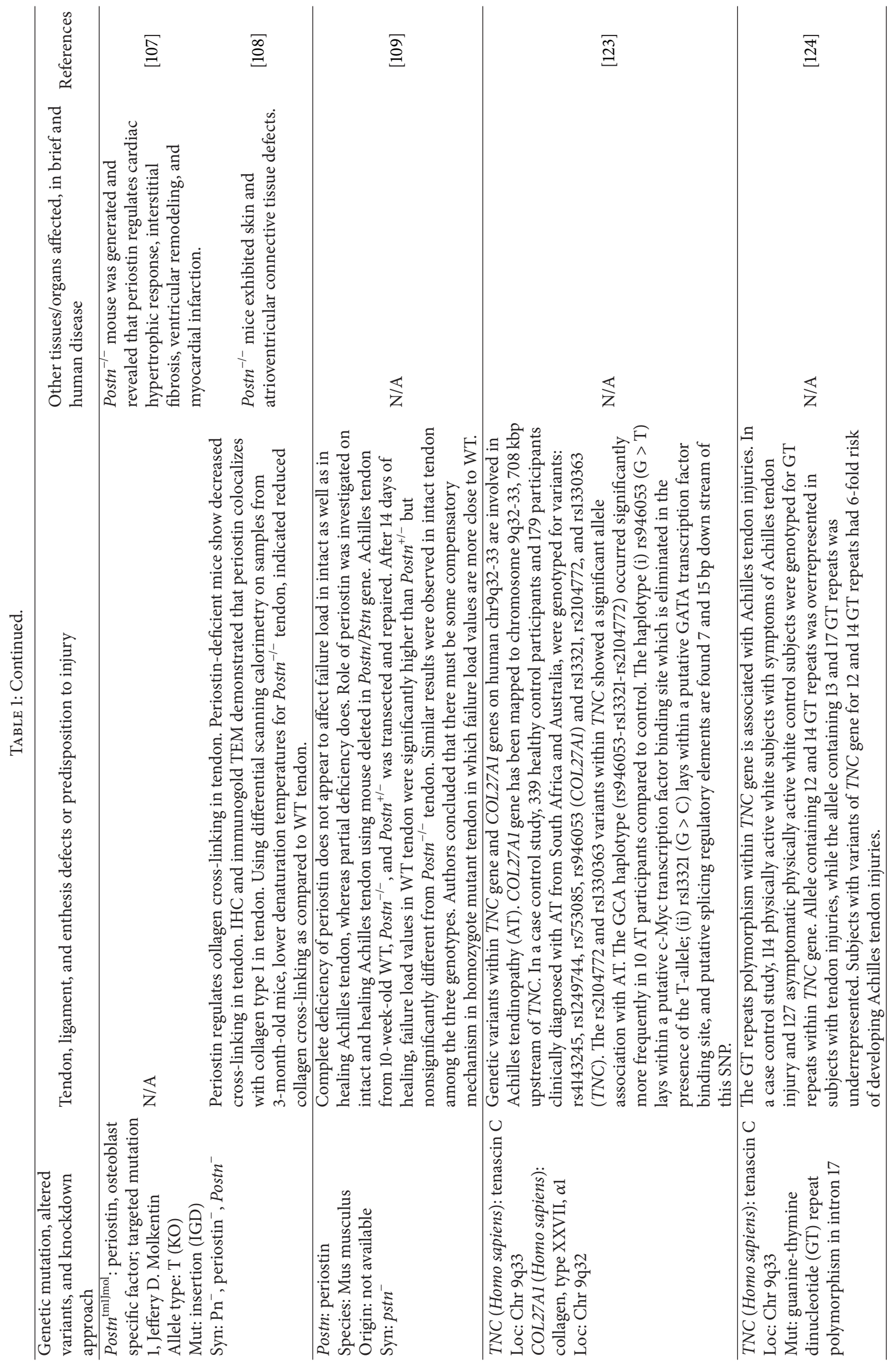




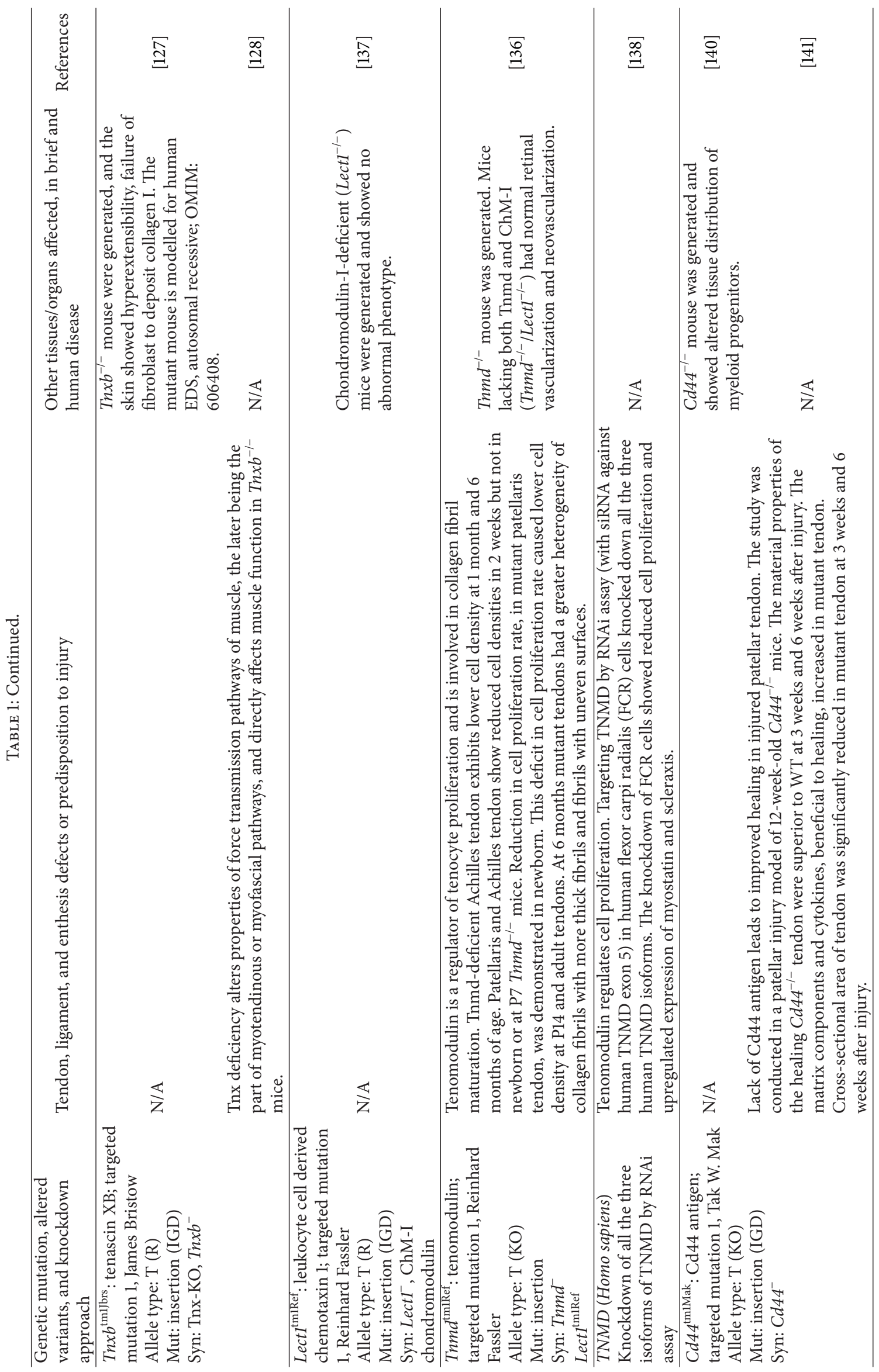




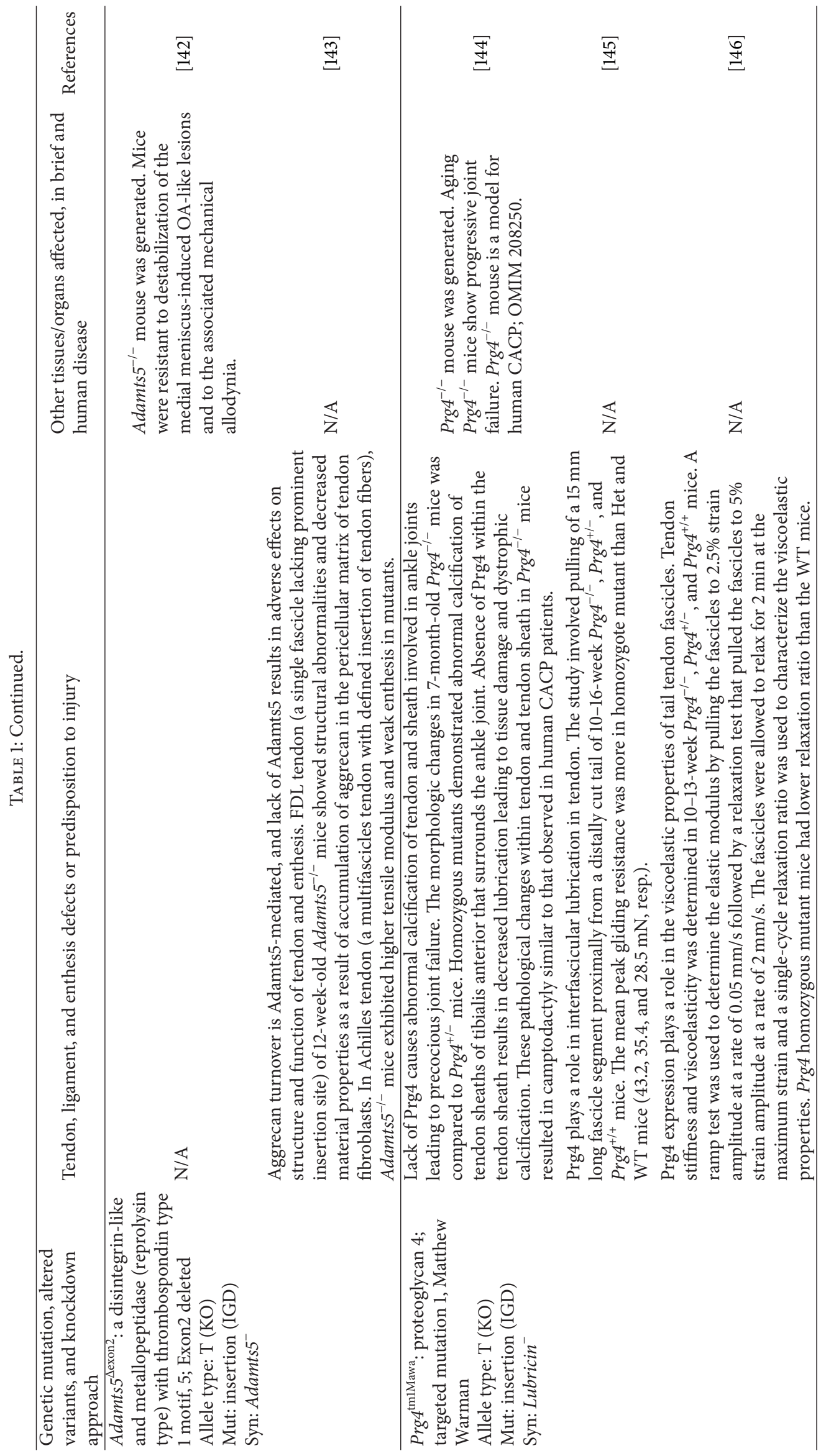




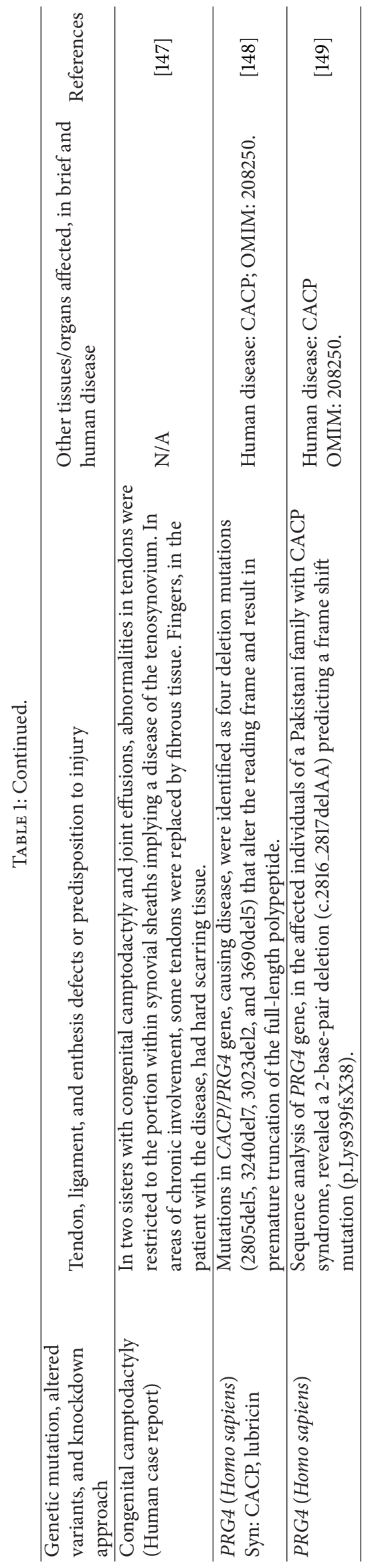


$\alpha 2(\mathrm{I})$ chains; however, in its absence, there is higher amount of cross-linked $\alpha 1$ (I) chains. This change in cross-linking pattern may be due to the presence of other SLRPs, for example, higher Lum in $\mathrm{Fmod}^{-/-}$tendon [27, Table I]. The formation of mechanically strong fibrils may require Fmodregulated crosslinking. The absence of Fmod would allow a higher activity of Lum that instead cross-links collagens into mechanically weaker fibrils [29].

\subsection{Biglycan (Bgn) and Decorin (Dcn) and Association with} Fmod, Lum, and Collagen. Biglycan and Dcn belong to the SLRPs class I subfamily. Both contain 12 LRRs. Biglycan has two attached GAG chains and Dcn has one. The GAG can be either chondroitin sulfate or dermatan sulfate depending on the tissue origin. Biglycan is found in several connective tissues, predominantly in articular cartilages. It is a homodimer and forms a ternary complex with microfibrillar-associated protein 2 and elastin and may be involved in collagen fiber assembly. Biglycan binds to Col I in the gap zone of the fibrils, and Dcn competes for that interaction [30]. One molecule of Dcn core protein interacts with four to six collagen molecules. Biglycan and Dcn bind to the same site in N-terminal region of collagen VI complex and compete for the same binding site [31]. Biglycan can connect collagen VI to collagen II [32].

2.2.1. Biglycan (Bgn) and Decorin (Dcn). The effects of the two GAG chains present on Bgn are reasonably different from the single GAG of Dcn. The switch in expression levels of these SLRPs during tendon development is demonstrated by the fact that Dcn protein increases gradually with development from P4 to P30, whereas Bgn core protein decreases from $\mathrm{P} 4$ to P30 in flexor tendon. The stage in normal tendon development (P30), where Dcn peaked and Bgn decreased to its lowest level, indicates that Dcn persists until thick fibrils are formed [33, Table I]. The two GAG chains are proper organizers in the formation of early fibrils, perhaps by controlling the multitudes of small fibrils that would otherwise assemble in an uncontrolled manner. Biglycan, and not $\mathrm{Dcn}$, is upregulated by $100 \%$ in compressed tendons where mechanical stress induces collagen fibrillogenesis [34]. Decorin-deficient mice showed abnormal collagen fibrils in FDL, and in tail tendon (Figure 3), the effect was more severe indicating the differential role of this proteoglycan in different tendons [33, Table I]. In the initial studies, when Danielson and coworkers knocked out the mouse for Dcn gene, they did notice similar severe phenotype in tail tendon collagen fibrils in Dcn-deficient mice [35, Table I] as also shown by Corsi and coworkers [36, Table I]. Reduced mechanical properties were recorded in FDL tendon in mature Dcn-deficient mice [33, Table I].

\subsubsection{Decorin (Dcn) and Periodontal Ligament (PDL).} Häkkinen and coworkers reported that Dcn plays role in maintaining structure and cellularity in PDL. In Dcn homozygote mutant mice, PDL collagen fibers are wider, random, and with varied small-sized fibrils. The mutation caused hypercellularity in PDL [37, Table I]. Ectopic overexpression of Dcn, in periodontal fibroblasts, suppressed the cell growth in vitro, indicating that Dcn regulates cell proliferation negatively in PDL [37, Table I]. Dourte and coworkers discovered that the viscoelastic and tensile dynamic modulus increased in the heterozygote $\left(\mathrm{Dcn}^{+/-}\right)$tendons in which a decrease in collagen content was also discovered as compared to WT tendons [38, Table I]. In another interesting study, Ilkhani-Pour and colleagues showed that injured Dcndeficient Achilles tendon heals better. Injured $\mathrm{Dcn}^{-/-}$tendons showed decreased tendon crosssection area, increased linear modulus, decreased $\tan (\delta)$, and increased dynamic modulus $\left|E^{*}\right|$ compared to WT Achilles tendon. Authors suggested that the deletion of Dcn during tendon healing might have reduced scarring and improved collagen fibrillogenesis [39, Table I].

\subsubsection{Decorin (Dcn) Structure and Function Affected by} Dermatan Sulfate Epimerase (Dse). It is worth mentioning an enzyme, dermatan sulfate epimerase (Dse), that impacts the property of SLRP containing chondroitin sulfate/dermatan sulfate (CS/DS) by converting glucuronic acid unit to iduronic acid. Chondroitin sulfate is an unbranched polymer chain composed of alternating glucuronic acid and $\mathrm{N}$ acetylgalactosamine units. In dermatan sulfate, D-glucuronic acid is converted to its epimer L-iduronic acid. The extent of this modification varies from a few percent of the glucuronic acid being epimerized to a predominant presence of iduronic acid and depends on the variable epimerase activity in tissues and on the core protein attached to the chain in CS/DS proteoglycans $[2,40]$. The name CS/DS denotes the hybrid nature of the chain. The altered CS/DS chains carried by Dcn affects tendon fibrillogenesis. Collagen fibrillogenesis in tail tendon in $D s e^{-/-}$mice was adversely affected with the presence of collagen fibrils with increased diameter [40, Table I]. A similar pattern in phenotype is observed in mice deficient in Dcn that showed fibrils with increased diameter in tail tendon $[33,35,36$, Table I].

\subsubsection{Lumican (Lum), Fibromodulin (Fmod), Dbl-KO (Lum} and Fmod), and Decorin (Dcn). Teeth in SLRPs-deficient mice $\left(\mathrm{Lum}^{-1-}, \mathrm{Fmod}^{-1-}, \mathrm{Fmod}^{-1-} / \mathrm{Lum}^{-1-}\right.$, and $\left.\mathrm{Dcn}^{-1-}\right)$ erupted normally but histology and electron microscopy revealed abnormalities in PDL collagen fiber bundles. Lumican-deficient mice showed collagen fibers with smaller diameter and with varied interfibers spaces, fibromodulindeficient fibers showed thicker bundles with poorly defined outlines [41, Table I]. On the other hand, in the mice deficient both in Fmod and Lum $\left(\right.$ Fmod $\left.^{-/-} / \mathrm{Lum}^{-/-}\right)$, PDL contained some of the attributes from both the single-KO mice. Interestingly, Dcn-deficient mice alone demonstrated that the PDL fiber bundles were more disrupted with more width as compared to all the other three mutants $\left(\mathrm{Lum}^{-/-}, \mathrm{Fmod}^{-/-}\right.$, and $\mathrm{Fmod}^{-/-} / \mathrm{Lum}^{-/-}$) [41, Table I].

2.2.5. Decorin (Dcn) and Collagen I (Col I). Investigations from Soslowsky laboratory showed the role of Dcn and collagen content on the tendon properties. In the first study, they reported how quasilinear viscoelastic properties of 

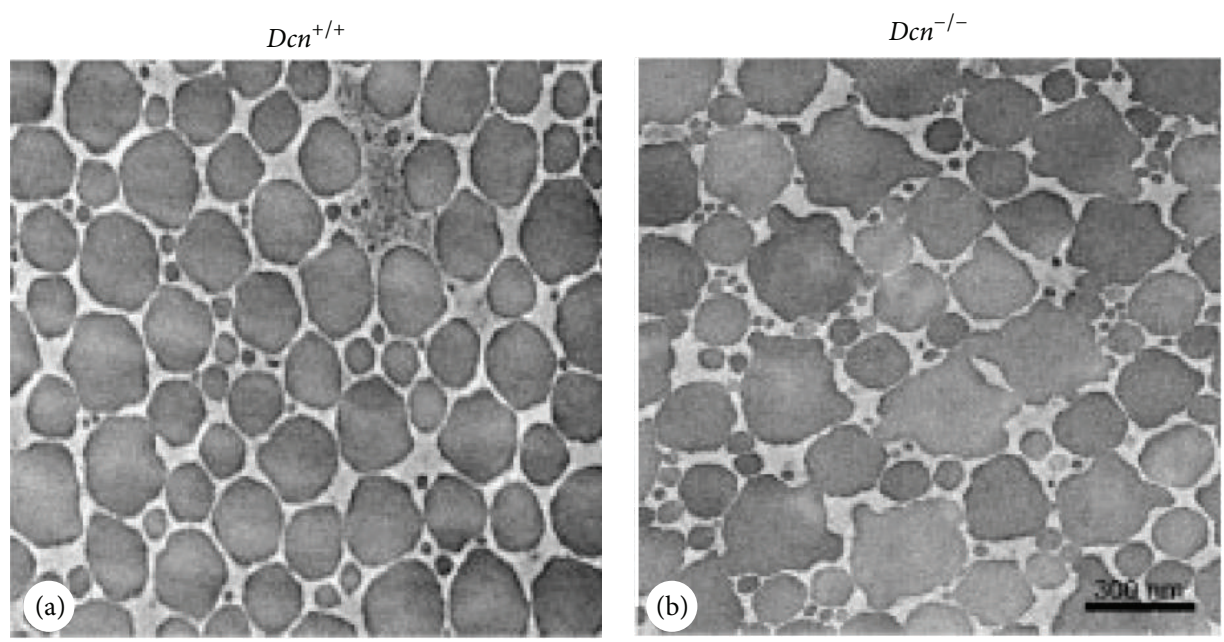

FIGURE 3: Decorin deficiency results in aberrant tendon collagen fibril structure. TEM of tail tendon of 7.5-month old mice showing transverse section of collagen fibrils. A larger fraction of fibrils are noncylindrical and structurally aberrant in homozygous mutant $\left(D c n^{-/-}\right.$, (b)) as compared to WT $\left(\mathrm{Dcn}^{+/+}\right.$, (a)) mouse (Reprinted from Zhang et al., 2006 [33], copyright @ 2005 Wiley-Liss, Inc. with permission).
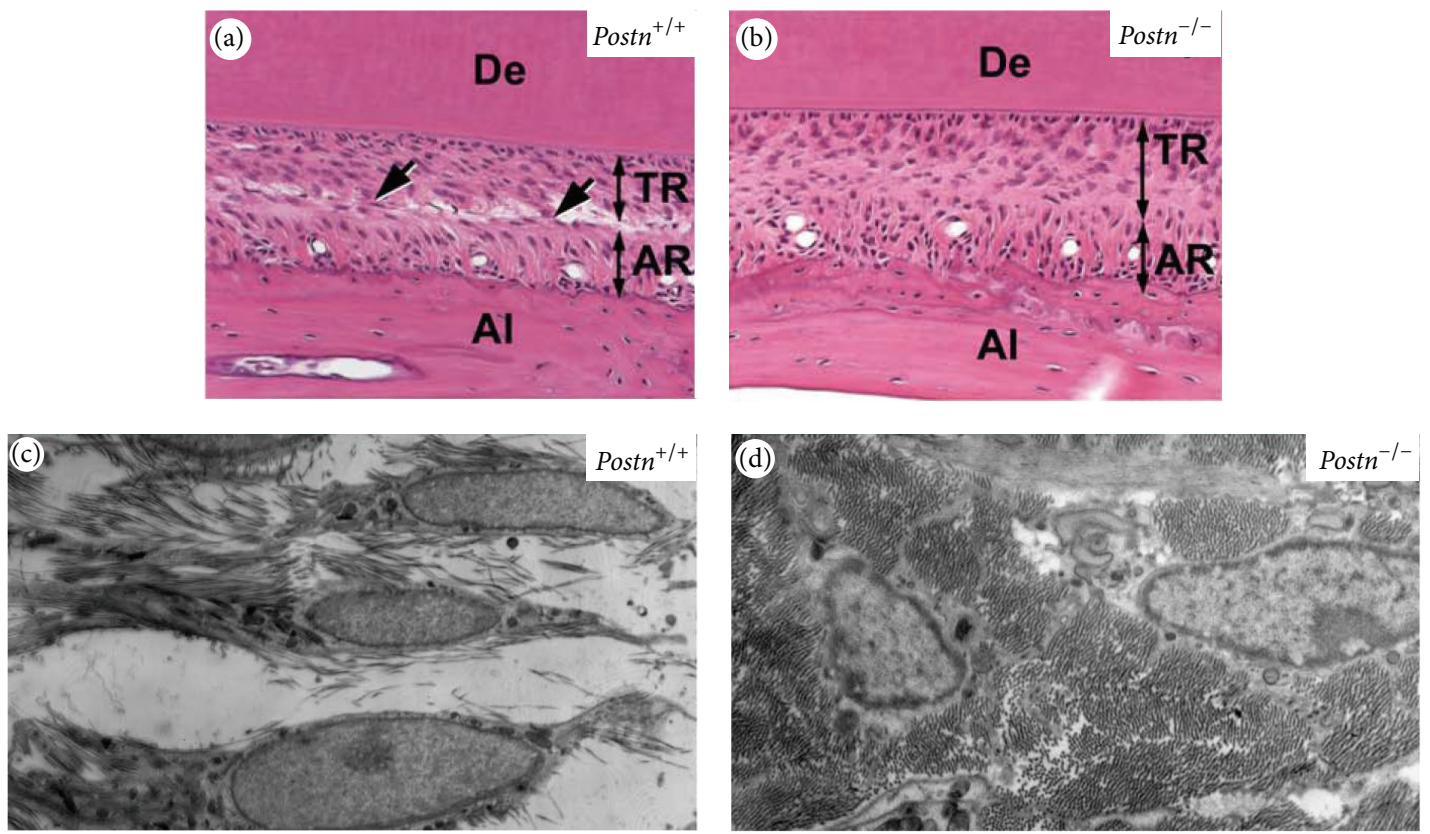

FIgUre 4: Remodeling of the PDL of incisors is defective in Postn ${ }^{-/-}$mice. H\&E-stained PDL section from 12week Postn $n^{+/+}$(a) and Postn ${ }^{-/-}$ (b) mice. Arrows indicate the shear zone, which is the boundary between the TR (tooth-related) and AR (alveolus-related) regions. The shear zone is clearly visible in 12 week old Postn ${ }^{+/+}$mouse (a) and absent in Postn ${ }^{-/-}$mouse (b). TEM of the incisor PDL shows evidence of digestion of collagen fibers in Postn ${ }^{+/+}$(c) but undigested and abundant collagen bundles in Postn ${ }^{-/-}$mice (d). De, dentin; Al, alveolar bone. (Reprinted from Kii et al., 2006 [102], with permission, Elsevier 2006, and thanks to Dr. A. Kudo for his generous approval.)

tendon are affected by their content [42, Table I]. The authors performed uniaxial tensile stress-relaxation experiment on tail tendon fascicles from mice at different developmental age and genotype groups, that is, 8-weeks $\mathrm{Dcn}^{-/-}$, 8-weeks Collal $^{\text {mov13/+ }}$ [43-45, Table I], 8-weeks control, and 3-weeks control mice. The viscoelastic properties demonstrated a larger and faster stress relaxation for Dcn-deficient mice, a smaller and slower stress relaxation for 3-weeks old mice with less collagen and more proteoglycan. The elastic parameter in 8-weeks control group was greater than the mice with reduced collagen $\left(\right.$ Colla1 ${ }^{\text {mov13/+ }}$ ) and with 3 -weeks control [42, Table I]. Another study, from the same group, proved that the viscoelasticity of tendon fascicle is affected by Dcn content but not by collagen alteration [46, Table I]. In this 
study, Robinson and co-workers studied the mechanical properties of tail tendon fascicles in mice of different genotypes and age groups: 8 -weeks $\mathrm{Dcn}^{-/-}, 8$ wks $\mathrm{Collal}^{\text {mov13/+ }}$ (mice with 50\% less Col I), 8-weeks Col1a1 ${ }^{\text {tm1Jae }} /$ Colla $1^{\text {tm1Jae }}$ (mice with accumulated Col I in soft tissues, [47, Table I]), 8-weeks control (normal mature mice), and 3-weeks control (immature mice with increased proteoglycan with GAGs in their tendon). Altered collagen in tail tendon fascicle in mice Collal ${ }^{\text {mov13/+ }}$ or Collal ${ }^{\text {tmlJae }} /$ Collat $^{\text {tm1Jae }}$ led to reduced failure load and stiffness with no changes in failure stress, modulus, or strain rate sensitivity. Decorindeficient fascicles had similar elastic properties as normal control fascicles but with reduced strain rate sensitivity. Fascicles from immature mice had inferior elastic properties but higher strain rate sensitivity [47]. Using the similar set of mice, tendon fascicle structure/function relationship was established using multiple regression models and relative contributions of seven different structural and compositional variables in predicting tissue mechanical properties [48, Table I]. GAG content was observed to be the strongest predictor of mechanical properties and was also well correlated with collagen content and mean collagen fibril diameter. Collagen fibril area fraction was a significant predictor only of material properties. This concluded that in a large multivariate model, GAG content is the largest predictor of mechanical properties $[48$, Table I].

\subsubsection{Biglycan (Bgn) and Fibromodulin (Fmod). By using} Bgn-deficient mice [49, Table I], Corsi and co-workers were able to show altered collagen fibrillogenesis in tail tendon [36, Table I]. Tendon from 2 month male hemizygous $\mathrm{Bgn}^{-/ 0}$ mice showed abnormal shaped fibrils, and with large diameters Bgn deficiency adversely affects the mechanical property of the healing bone insertion site of the patellar tendon fibers 4weeks after surgery. Collagen fibril diameter distribution was disturbed in mutant mice [50, Table I]. Biglycan is expressed in PDL, alveolar bone (AB), at the AB-PDL attachment site, and at the cementum-PDL attachment site in mice. Histomorphometric analysis of X-ray $\mu \mathrm{CT}$ images of Bgn-deficient cementum-PDL-AB complex exhibited abnormalities with higher PDL space, compromising the integrity of periodontal tissue [51, Table I]. Double homozygote mutants for Bgn and Fmod genes showed severe defects in mouse joint tendons that led the mouse to develop OA. Quadriceps tendon showed altered collagen fibrils in all the mutants (Bgn-KO, Fmod-KO, and $\mathrm{Dbl}-\mathrm{KO}$ ) but the severity of alteration was more in DblKO. Reduced stiffness was noticed in patellar tendon at an early age [52, Table I]. In fact, Dbl-KOs developed premature $\mathrm{OA}$ and were at the predisposition to OA. The mutants represent a model for spontaneous OA, early-onset, and rapid progression of OA [52, Table I]. Working on the same DblKO mice, there appeared an elegant study from Young's laboratory. The authors used patellar tendon from Dbl-KO $\left(\mathrm{Bgn}^{-/ 0} / \mathrm{Fmod}^{-1-}\right)$ and demonstrated the existence of an ECM niche for tendon stem/progenitor cells (TSPCs). Patellar tendon in Dbl-KO mice was thinner and hypercellular, and exhibited disorganized collagen fibers and gaps [53, Table I]. The TSPCs from Dbl-KO mice presented higher number of colonies in cell culture when compared to TSPCs from WT mice indicating that the cells loose their "stemness" when isolated from mutant tendons. The authors hypothesized that an ECM-rich niche, organized by Bgn and Fmod, controls the self-renewal and differentiation of TSPCs in tendon [53, Table I]. In another study on these mutant mice, Kilts and colleagues showed that the mice deficient in Bgn, Fmod, or both developed ectopic ossification in tendon with aging in male and female mice. At 3-month old, all the mutants displayed torn cruciate ligaments and ectopic ossification in their quadriceps tendon, menisci, cruciate ligament, and patellar ligament; the phenotype was least severe in Fmoddeficient, intermediate in Bgn-deficient, and the most severe in Dbl-KO mice [54, Table I].

2.2.7. Biglycan (Bgn) and Decorin (Dcn). By using tendons from different loading regions of mutant mice deficient in Bgn and Dcn, Robinson and co-workers were able to demonstrate that tendons are tailored according to their location [55, Table I]. Mechanical properties of tail tendon fascicle did not show any change due to deficiency of either proteoglycan, whereas the loss of Dcn affected patellar tendon causing an increase in the modulus and stress relaxation but had little effect on FDL tendon. Dunkman and co-workers showed that aged patellar tendon has decreased dynamic modulus and viscoelastic property, decreased cellularity and alteration in tenocyte shape, and reduced collagen fibers alignment as compared to mature tendon [56, Table I]. Interestingly, Dcn-deficient tendons exhibited decreased effects of aging compared to the biglycan deficient or WT due to reduced detrimental effects on collagen fibrils [56, Table I]. Connizzo and co-workers studied realignment of collagen fibers and mechanical properties of aging supraspinatus tendons at 90 570 days of age in proteoglycan-deficient mice. The Bgn- or Dcn-deficient tendon showed altered mechanical properties with age, predominantly at the insertion site. Changes in realignment throughout age were not found in the midsubstance of the Bgn-deficient tendons or at the insertion of Dcn-deficient tendons. The study showed that Dcn and Bgn contribute to tendon's response to load, in particular with realignment of collagen fibers [57, Table I]. Both Bgn and Dcn have a role in the cornea fibrillogenesis [58]. Biglycan is upregulated in Dcn-deficient cornea and is considered to replace the function of Dcn. In contrast, Dcn reactivity was comparable in Bgn-deficient mice.

\subsection{Asporin (Aspn)/Periodontal Ligament-Associated Protein} 1 (PLAP-1). Asporin contains 11 LRRs and 1 LRRNT domain. It is a critical regulator of TGF $\beta$ in articular cartilage and plays an essential role in cartilage homeostasis and OA pathogenesis. Asporin blocks chondrogenesis and inhibits TGF $\beta 1$-induced expression of matrix genes. Knockdown of Aspn increases the expression of cartilage marker genes and TGF $\beta 1$, which, in turn, stimulates Aspn expression in articular cartilage cells, suggesting that Aspn and TGF $\beta 1$ form a regulatory feedback loop. Asporin inhibits TGF $\beta /$ Smad signaling upstream of TGF $\beta$ type I receptor activation in vivo by colocalizing with TGF $\beta 1$ on the cell surface and 
blocking its interaction with the TGF $\beta$ type II receptor [59]. Asporin interacts with type I collagen. Decorin can inhibit collagen binding (Q99MQ4 at http://www.uniprot.org/). The LRR 5 repeat of Aspn can inhibit BMP2-induced cytodifferentiation. The induction of mutation in LRR5 within Aspn rescued the inhibitory effect of Aspn on BMP2 [60]. Asporin can bind collagen at the same site as Dcn, but it drives the biomineralization of collagen in contrast to Dcn and Bgn [61]. Asporin binds collagen type I. This binding is inhibited by recombinant Aspn fragment LRR 10-12 and by full-length Dcn, but not by Bgn. The polyaspartate domain of Aspn binds calcium and regulates hydroxyapatite formation in vitro. In the presence of Aspn, the number of collagen nodules as well as osterix and Runx 2 mRNA, increased. Moreover, Dcn or the collagen-binding Aspn fragment LRR 10-12 inhibited the proosteoblastic activity of full-length Aspn. Thus Aspn and Dcn compete for binding to collagen and the polyaspartate in Aspn directly regulates collagen mineralization [61].

Asporin is expressed at higher level in the heart and specifically and predominantly in the PDL. During tooth development, strong expression is seen in the dental follicle, which is the progenitor tissue that forms cementum, alveolar bone, and the PDL $[62,63]$. At E15.5, Aspn RNA expression is prominent in the developing mouse skeleton, particularly in the perichondrium/periosteum of cartilage/bone, and is found in other specialized connective tissues such as tendon, sclera, the connective tissue sheath surrounding muscle, and dermis [64].

Aspn knockdown studies showed that it negatively regulates PDL differentiation and mineralization to ensure that the PDL is not ossified, maintains homeostasis of the tooth-supporting system, and also inhibits Bmp2-induced cytodifferentiation of PDL cells by preventing its binding to BmpR1B, resulting in inhibition of Bmp-dependent activation of SMAD proteins. [62, Table I]. Li and coworkers reported that micro-RNAs miR-21 and miR-101 regulate Aspn expression in PDL cells. By using dual luciferase reporter assay and RNA expression assays, the group showed that miR21 and miR-101 target Aspn to regulate its expression during osteogenic differentiation of PDL cells [65, Table I].

\section{Matricellular Proteins}

Matricellular proteins are extracellular matrix proteins that modulate cell-matrix interactions and cell function and do not seem to have a direct structural role. The family includes thrombospondin-1, thrombospondin-2, osteopontin/Spp1, osteonectin/Sparc, periostin, tenascin C, and tenascin X. Expression of matricellular proteins is usually high during embryogenesis, but nearly absent during normal postnatal life. Interestingly, it reappears in response to injury [66].

3.1. Thrombospondin 2 (Thbs2/Tsp2). Thrombospondins are secreted, multimeric multidomain glycoproteins that function at the cell surfaces and the ECM and belong to thrombospondin family. They act as regulators of cell interactions in vertebrates. Thrombospondins consist of two subfamilies,
A and B [67]. The subfamily A, proteins of Tsp1 (Thps1) and Tsp2 (Thbs2), assemble as homotrimer (P35441 and Q03350 at http://www.uniprot.org/uniprot/ resp.). The subfamily B of thrombospondins, consisting of Tsp3, Tsp4, and cartilage oligomeric matrix protein (Comp, also designated Tsp5), assemble as pentamers [67].

Thrombospondin 2 is a ligand for CD36 via the TSPI repeats and delivers an antiangiogenic effect $[68,69]$. It is homotrimeric and disulfide-linked and interacts (via the TSP type I repeats) with heregulin, and the interaction blocks the antiangiogenic effect of Tsp2 with CD36 [69]. Thrombospondin 2 can bind to fibrinogen, fibronectin, laminin, and collagen V [69-72]. Heparan sulfate proteoglycan, low-density lipoprotein receptor related protein, and $\alpha \mathrm{V} \beta 3$ integrin have also been shown to be receptors for Tsp2 $[69,73,74]$. Adult mice do not express Tsp2 in collagen fibers of skin and tendon. Also tendon fibroblasts are not immune-reactive to Tsp2. Embryonic tendons, which are more cellular and grow rapidly, display high levels of Tsp2 transcript [75, 76]. Tsp2 is required for proper collagen fibrillogenesis in skin and tendon [77, Table I] and its absence disrupts fibroblast cell-matrix interaction during postnatal development of Tendon [78, Table I].

\subsection{Secreted Phosphoprotein 1 (Spp1)/Osteopontin (Opn)/Bone} Sialoprotein 1. Secreted phosphoprotein 1 is expressed in many tissues and cell types and found in body fluids [79]. The secreted protein is heavily modified posttranslationally by $\mathrm{O}$-glycosylation, sulfation, and serine/threonine phosphorylation, the processes are heterogeneous and vary according to the cell origin $[80,81]$. Sppl is extensively phosphorylated on serine residues [82]. The functional domains of Spp1 are well conserved among species the central integrin attachment motif GRGDS, thrombin cleavage site, cryptic integrin attachment motif "SVVYGLR", and mineral binding polyaspartate region. Many of the phosphorylated and glycosylated sites are well conserved [83].

Spp1 binds tightly to hydroxyapatite and forms an integral part of the mineralized matrix. It plays a role in cell-matrix interaction [84]. It acts as a cytokine involved in enhancing production of INF- $\gamma$ and IL-12 and reducing IL-10 and is essential in the pathway that leads to type I immunity [84]. This cytokine and mineral matrix protein plays an important role in a number of physiological and pathological events, including tissue repair, regulation of bone metabolism, inflammation, and immunity [85]. Opn/Spp1 was highly upregulated during the muscle regeneration process induced by injection of the snake venom, cardiotoxin. SPP1 is expressed in the cells around calcified tendinitis. Spp1 plays role in the process of calcification of rotator cuff tendons [86]. Spp1 mRNA is expressed in normal patellar tendon of WT mice. By IHC, WT tendon expresses Spp1 protein in fibroblasts the latter exists in the interstitial space in tendon matrix [85]. Genetic deletion of Spp1 gene showed normal development [87, Table I]. However, $\operatorname{Spp} 1^{-/-}\left(\mathrm{Opn}^{-/-}\right)$mice demonstrated that Spp1 plays a role in stress-induced tendon remodeling $[85$, Table I]. 
3.3. Secreted Protein Acidic and Rich in Cysteine (Sparc)/Osteonectin (ON). Sparc regulates the cell growth through interactions with the ECM and cytokines. It binds to calcium, copper, and several types of collagen, albumin, thrombospondin, PDGF, and cell membranes. There are two calcium binding sites: an acidic domain that binds 5 to $8 \mathrm{Ca}^{2+}$ with low affinity and an EF-hand loop that binds $\mathrm{a} \mathrm{Ca}^{2+}$ ion with high affinity. Sparc protein, secreted in ECM, is present in and around basement membrane and has been shown in mineralized and nonmineralized tissues [88]. It belongs to SPARC family and contains 1 EF-hand domain, 1 follistatin-like domain, and 1 Kazal-like domain. Sparc is expressed at high levels in tissues undergoing morphogenesis, remodeling, and wound repair [89]. It is a collagen-binding protein that has a great impact on ECM structure and function. It is glycosylated posttranslationally and is secreted in most tissues. Sparc is considered as a matricellular protein that modulates interactions between the cell and ECM and influences the efficacy of certain growth factors [90]. The Sparc-deficient mice revealed a function of Sparc in the deposition and accumulation of fibrillar collagen in tissues $[89,91]$. Sparc plays role in pericellular processing of procollagen and functions in collagen turnover at the cell surface [91].

Collagen in the PDL has highest turnover rate in the body [92]. Hence, proteins that influence collagen deposition and turnover, such as Sparc, are expected to influence maintenance of structure and function of PDL. Sparc plays a role in human PDL disease, as demonstrated by its increased expression in gingival crevicular fluid of patients with periodontal disease [93]. Initial phenotype of Sparc ${ }^{-/-}$mice showed that Sparc is essential for the maintenance of lens transparency [94, Table I]. The Sparc-deficient mice suggest that Sparc function is related to collagen binding and to the regulation of ECM assembly and turnover. Specifically, Sparcdeficient mice had less collagen content in PDL [95, Table I]. Likewise, in lipopolysaccharide-induced inflammatory periodontal disease, Sparc-deficient mice lost more collagen in the PDL than the WT [96, Table I]. Based on their investigations [95, 96, Table I], Trombetta-Esilva and Bradshaw suggested a very convincing model of cellular mechanisms in that Sparc binds to procollagen the moment it is secreted from the cell (or procollagen is secreted already bound by Sparc) and prevents interaction of procollagen with cellular receptors, such as discoidin domain-containing receptor 2 (DDR2) and integrin $\alpha_{2} \beta_{1}$ or others. The procollagen is then appropriately processed and incorporated into collagen fibrils. In the absence of Sparc, procollagen accumulates at the cell surface and is inefficiently incorporated into the collagenous ECM, resulting in less total collagen and fewer thick collagen fibers [97].

3.4. Periostin (Postn). Periostin has enhanced expression in periosteum and PDL. Periostin mRNA was shown to be upregulated at the sites under tension in bone and periodontal tissue remodeling after mechanical stress during experimental tooth movement [98]. It has been shown to play a role during developmental and wound repair [99].
Periostin mRNA expression level was higher during tendon graft healing process $(112,113)$. Periostin is a $90 \mathrm{kDa}$ TGF $\beta$ induced secreted protein. It is a disulfide-linked protein. It is a member of fasciclin I family, which includes TGF $\beta$-induced protein and drosophila fasciclin I. Periostin domains have the following characteristics: the EMI domain binds to type I collagen, fibronectin, and Notch1, and the Fas I domains bind to tenascin-C and BMP-1. The $\mathrm{C}$-terminal domain gives rise to splice variants and contains proteolytic cleavage sites [100].

Periostin-deficient mice generated by Rios et al. [101, Table I] and by Kii et al. [102, Table I] both showed the fragility of the teeth due to defective PDL. In the embryonic teeth of the mouse mandible, Postn was localized to the interface between the inner enamel epithelium and preodontoblasts as well as in the mesenchymal tissues around the cervical loop [103]. At P7, the Postn protein was restricted to the fibrous bundles in PDL [104]. Postn is involved at sites of cell-to-matrix interaction, serving as an adhesive equipment for bearing mechanical forces including tooth eruption and transducing the occlusal force that activates latent TGF $\beta$ to enhance Postn expression [105, Table I]. Consistently, Postn $^{-/-}$mice showed defective eruption of their incisors $[102$, Table I]. The abnormal presence of nondigested collagen fibrils in the shear zone in the Postn ${ }^{-/-}$PDL [102, Table I, Figure 4] was explained by the low activity of matrix metalloproteinases, which are efficiently secreted following their induction by Postn [106]. Due to preferential expression of Postn in PDL and interaction with collagen fibrils, Post ${ }^{-/-}$ mice showed that Postn is required for the maintenance of the PDL integrity in response to mechanical stress [101, Table I], for the integrity and function of PDL during occlusal loading [104, Table I] and for the remodeling of incisors [102, Table I]. Other mutant Post $n^{\mathrm{tm} 1 \mathrm{Jmol}} /$ Post $^{\mathrm{tm} 1 \mathrm{Imol}}$ mice, generated by Oka et al. [107], revealed that Postn ${ }^{-/-}$mice exhibit decreased cross-linking in tendon [108, Table I]. In another recent finding, WT mice tendon had higher failure load than Postn heterozygote mutants only but not than homozygote mutants during healing process $[109$, Table I].

3.5. Tenascin $C(\operatorname{Tnc})$ and Tenascin $X(\operatorname{Tn} x)$. Tenascins are a family of ECM proteins that evolved in early chordates [110]. There are four family members: tenascin $\mathrm{X}, \mathrm{R}, \mathrm{W} / \mathrm{N}$, and C. Tenascin $\mathrm{X}$ associates with type I collagen. The expression of tenascin $\mathrm{C}$ and tenascin $\mathrm{W} / \mathrm{N}$ is developmentally regulated, and both are expressed during the disease state [110]. Tenascin $\mathrm{C}$ is a ligand for integrins $\alpha 8 / \beta 1, \alpha 9 / \beta 1$, $\alpha \mathrm{V} / \beta 3$, and $\alpha \mathrm{V} / \beta 6$ [111]. It is a homohexamer and disulfidelinked and is N-glycosylated [110]. It is expressed in nervous, skeletal, and vascular systems in embryonic stage and is involved in organ morphogenesis. In adult, tenascin $\mathrm{C}$ is expressed in dense connective tissues, smooth muscle, and stem cell niches of brain and bone marrow [110]. In disease, TNC is associated with asthma, fibrosis, wound healing, infection, tumor invasion, and metastasis [110]. Tenascin $\mathrm{C}$ is expressed during flexor tendon graft healing process during granulation phase $[112,113]$. Tnc monomer in mouse comprises of 15 EGF-like domains, one fibrinogen C-terminal 
domain, and 14 fibronectin type-III domains (Q80YX1 at www.uniprot.org/uniprot/).

A large number of Achilles tendon injuries are associated with participation in sports [115]. Tenascin C is expressed in tendons [116]. In normal adult tendons, it is expressed predominately in regions transmitting high levels of mechanical force, such as the myotendinous and osteotendinous junctions $[117,118]$. The protein is also expressed around the cells and collagen fibers of the Achilles tendon [119]. In addition, Järvinen and colleagues have shown that the expression of the TNC gene is regulated in a dose-dependent manner by mechanical loading in tendons $[118,119]$. Isoforms of the protein, with distinct functions, are produced by alternative splicing of the primary transcript [103, 120, 121]. Healthy tendons express a small $200 \mathrm{kDa}$ TNC isoform, while degenerate tendons express a functionally distinct larger $300 \mathrm{kDa}$ isoform [103]. Ireland and coworkers have reported an increase in TNC expression in biopsy samples of chronic Achilles tendinopathies [122]. Human genetic studies show that chromosome 9q33 is involved in the predisposition risk of Achilles tendon injuries; for example, COL27AI rs946053, TNC rs13321, and TNC rs2104772 variants are significantly associated with risk of Achilles tendon injury in a South African and Australian subjects [123, Table I]. Earlier studies by Mokone and associates reported the association between a dinucleotide (GT) microsatellite marker within intron 17 of TNC and Achilles tendon injuries [124, Table I].

Tenascin $\mathrm{X}$ belongs to the tenascin family and contains 19 EGF-like domains, one fibrinogen C-terminal domain and 32 fibronectin type-III domains. Tenascin $\mathrm{X}$ mediates interactions between cells and the ECM. TNX is a large $450 \mathrm{kDa}$ ECM protein expressed in a variety of tissues including skin, joints, and blood vessels. Deficiency of TNX causes a recessive form of EDS characterized by joint hypermobility, skin fragility, and hyperextensible skin. Skin of TNX deficient patients shows abnormal elastic fibers and reduced collagen deposition. TNX is homotrimer and interacts with type I, III, and V collagens and tropoelastin via its 29th fibronectin type-III domain [125]. It is highly expressed in fetal adrenal and testis, fetal smooth, and striated and cardiac muscle. Short isoform XB is only expressed in the adrenal gland. Expression levels are lower in adults than in children [126]. Tenascin X homozygote mutant mice showed skin hyperextensibility [127, Table I]. Further analysis of this mice revealed that tenascin $\mathrm{X}$ is required for force transmission of the myotendinous or myofascial pathways [128, Table I].

\section{Glycoproteins, Adamts5, and Other Proteoglycans}

4.1. Tenomodulin (Tnmd) and Chondromodulin-I (ChMI)/Leukocyte Cell-Derived Chemotaxin 1. Tenomodulin is a member of a family of type II transmembrane glycoproteins. Tnmd transcripts have been found in hypovascular tissues such as tendons and ligaments but the biological activity of Tnmd has not yet been fully explored. Tnmd has been suggested to play a role in tendon development. The Tnmd gene is predominantly expressed in tendons, ligaments, and the eye $[129,130]$, but low levels of mRNA transcripts have been identified in some other tissues including cartilage [129]. Chondromodulin-I (encoded by Lect1) is a homologue of Tnmd and is highly expressed in cartilage and weakly expressed in some other tissues $[129,131,132]$. Each of the two proteins has distinct and overlapping expression pattern in tissues. Both the proteins contain two extracellular domains: BRICHOS and a C-terminal cysteine-rich domain [133]. The recombinant C-terminal cysteine-rich domain of ChMI causes increased proliferation of primary chondrocytes [132], whereas endothelial proliferation was inhibited by the ectopic endothelial expression of the C-terminal cysteinerich domain of either TNMD or ChM-I [134, 135].

Tenomodulin-deficient mice showed reduced cell numbers in adult tendons and a decrease in tenocyte proliferation at newborn stage indicating the role of Tnmd in tenocyte proliferation. In addition, the altered structure of adult collagen fibrils suggests an involvement of Tnmd in postnatal tendon maturation, though the angiogenesis was unchanged in tendons in Dbl-KO mice for Tnmd and ChM-I [136, 137, Table I]. The knockdown of tenomodulin in human flexor carpi radialis cells by RNAi approach reduced the cell proliferation and upregulated expression of myostatin and scleraxis indicating a potential negative feedback loop between TNMD and its regulators [138, Table I]. Scleraxis positively regulates the expression of TNMD, a differentiation marker of tenocytes [139].

4.2. Cd44 Antigen (Cd44). CD44 is a single-pass type I membrane glycoprotein, also called hyaluronate receptor, and is a key mediator during normal wound healing, inflammation, and fibrotic healing process. The CD44 glycoproteins are members of hyaluronate receptor family of cell adhesion molecules. CD44 contains one extracellular lectin-like LINK domain that is responsible for hyaluronan binding. The major ligand is hyaluronate that is an abundant extracellular polysaccharide found in mammalian ECM, but CD44 has many varied functions depending on the extracellular structure of the protein, which can be produced in a myriad of isoforms. The wide range of functional proteins is produced from a single gene by both alternative splicing and posttranslational modifications [150]. CD44 is N-glycosylated, Oglycosylated, and phosphorylated and contains chondroitin sulfate glycans that can be more or less sulfated. There are two allelic forms of this glycoprotein, PGP-1.1 and PGP-1.2. The expressed product is PGP-1.1 (Ly-24.1). One of the major roles of CD44 is to mediate the uptake and clearance of hyaluronate.

Hyaluronic acid is abundant in tendons [151]. During adult tendon healing, CD44 and hyaluronic acid levels are elevated [152]. However, during scarless fetal healing, CD44 expression is downregulated [153] and hyaluronan levels surpass those of healing adult tendons. Higher levels of hyaluronic acid were shown to be beneficial in regenerative wound experiments [125]. Cd44-deficient mouse was generated by Tak Mak laboratory and the homozygous mutant mice showed abnormal hematopoiesis [140, Table I]. Interestingly, the study from Louis Soslowsky laboratory on these mutants 
further elaborated that injured patellar tendon heal better in Cd44-deficient mice than WT control mice [141, Table I] simulating the scarless fetal healing which occurs in the environment of low level of Cd44.

4.3. A Disintegrin and Metalloproteinase with Thrombospondin Motifs 5 (Adamts5) Cleaves Aggrecan. The ADAMTSs are a group of complex proteases found both in mammals and invertebrates. The complete human family has $\approx 20$ ADAMTS genes [154]. The ADAMTSs are extracellular multidomain enzymes with multiple functions: (i) collagen processing as procollagen $\mathrm{N}$-proteinase, (ii) cleavage of the matrix proteoglycans aggrecan, versican, and brevican, (iii) inhibition of angiogenesis, and (iv) blood coagulation homoeostasis as the von Willebrand factor cleaving protease [154]. Adamts5 is comprised from N- to C-terminus: (i) a signal peptide, (ii) a prodomain, (iii) a metalloproteinase domain, (iv) a disintegrin domain, (v) a thrombospondin type motif (TSP Type-I), (vi) a cysteine-rich domain, (vii) a spacer region, and (viii) TSP type-I motif [149]. ADAMTS5 is a C- and O-glycosylated molecule. The spacer domain and the TSP type-1 domains are important for a tight interaction with ECM. The conserved cysteine present in the cysteine-switch motif binds to the catalytic zinc ion, inhibiting the enzyme. The dissociation of the cysteine from the zinc ion upon the activation-peptide release activates the enzyme (Q9R001 at www.uniprot.org/uniprot/). The precursor is cleaved by a furin endopeptidase. Adamts 5 cleaves aggrecan, a cartilage proteoglycan, and is involved in its turnover. It plays an important role in the destruction of aggrecan in arthritic diseases and plays a role in proteolytic processing mostly during the peri-implantation period. Adamts5 cleaves aggrecan at the 392-Glu-|-Ala-393 site (Q9R001 at www.uniprot.org/uniprot/).

Aggrecan is most abundant in regions of tendon that experience mechanical compression and at enthesis [155]. Proteolytically degraded aggrecan has also been identified in tensional regions of normal adult bovine deep flexor tendons [156]. Disease ligaments from horses with degenerative suspensory ligament desmitis (DSLD) contain elevated levels of intact aggrecan and fragments generated by ADAMTS activity [157]. ADAMTS5 was abundant in the affected ligament but it was found to be complexed with hyaluronan around chondroid cellular clusters, and no active forms could be detected in these extracts. Genetically deleted mice for Adamts 5 cause aggrecan accumulation and affect the aggrecan turnover adversely. The accumulated aggrecan in tendon, in turn, affects the tendon functions adversely $[142,143$, Table I $]$.

4.4. Proteoglycan 4 (Prg4)/Lubricin/Superficial Zone Proteoglycan. Proteoglycan 4/lubricin plays a role in boundary lubrication within articulating joints, prevents protein deposition onto cartilage from synovial fluid, inhibits the adhesion of synovial cells to the cartilage surface, and prevents the articular chondrocytes apoptosis. Prg4 is a homodimer, disulphide-linked, and a secreted glycoprotein $[158,159]$. It is highly expressed in cartilage, bone, and liver. It is expressed on the surface of chondrocytes and in synovial intimal cells $[144,160]$. First detected, at the joint forming surface at E15.5 after cavitation, and at later stages of morphogenesis, strong expression is observed in superficial zone chondrocytes and in the newly forming synovium [144]. The molecule is $\mathrm{N}$ - and O-glycosylated and contains GAGs chondroitin sulfate and keratan sulfate $[161,162]$.

Different forms varying of Prg4 in molecular weight have been observed. Such forms are possibly due to different levels of glycosylation and protein cleavage. Prg4 contains two hemopexin-like domains and two somatomedin-B domains (Q9JM99 at www.uniprot.org/uniprot/). Prg4/lubricin is present in tendons, but its ability to improve tendon gliding was unknown until in vitro studies indicated that lubricin affects surface gliding and decreases gliding resistance [163]. Lubricin was found both on the flexor digitorum profundus tendon surface and at the interface of collagen fiber bundles within the tendon, where the cells are subjected to shear force in addition to tension and compression [164]. Six Nterminal splicing variants were identified from six distinct anatomical regions of flexor tendon. The variants with larger size were noted in regions subjected to significant shear and compressive forces [164]. The sheaths of the fascicles of the infraspinatus tendon near the bone-insertion site contain lubricin, indicating that this lubricating protein may be facilitating interfascicular movement. The fact, considering that the crimp pattern of fascicles changes with location in the tendon, provides support for the supposition that fascicles move relative to one another as the tendon is loaded, underscoring the importance of a lubricating protein in the layer separating the fascicles [165]. Mechanical loading has been shown to affect lubricin expression in flexor tendons, resulting in a $40 \%$ reduction of lubricin content in experimental non-weight-bearing flexor tendons [166].

Prg4/lubricin-deficient mice demonstrated abnormal calcification of tendon sheaths of tibialis anterior that surround the ankle joint. Absence of Prg4/lubricin within the tendon sheath results in decreased lubrication that led to tissue damage, matrix remodeling, and dystrophic calcification. These pathological changes led to camptodactyly similar CACP in human [144, Table I]. Lack of Prg4/lubricin did not affect Young's modulus in mice but rather it altered viscoelastic properties of tail tendon fascicles [146, Table I]. Prg4-deficient mice demonstrated abnormal calcification in joint tendons and sheaths leading to joint failure and that resulted in camptodactyly similar to human CACP patients [147, Table I]. Kohrs and colleagues demonstrated the reduction in lubrication in Prg4-KO mouse and the tail tendon exhibited increased intrafascicular resistance ex vivo [145, Table I]. In human patients with congenital camptodactyly and joint effusions, abnormalities in tendons were restricted to sheath [147, Table I]. Marcelino and colleagues showed that several mutations in human PRG4/lubricin are responsible for the cause for human CACP that alter the reading frame and result in premature truncation of the full-length polypeptide [148, Table I]. A deletion mutation was found in Prg4 gene in a family with CACP. Sequence analysis of Prg4 gene in the affected individuals revealed a 2-base-pair deletion predicting a frame shift mutation [149, Table I]. 

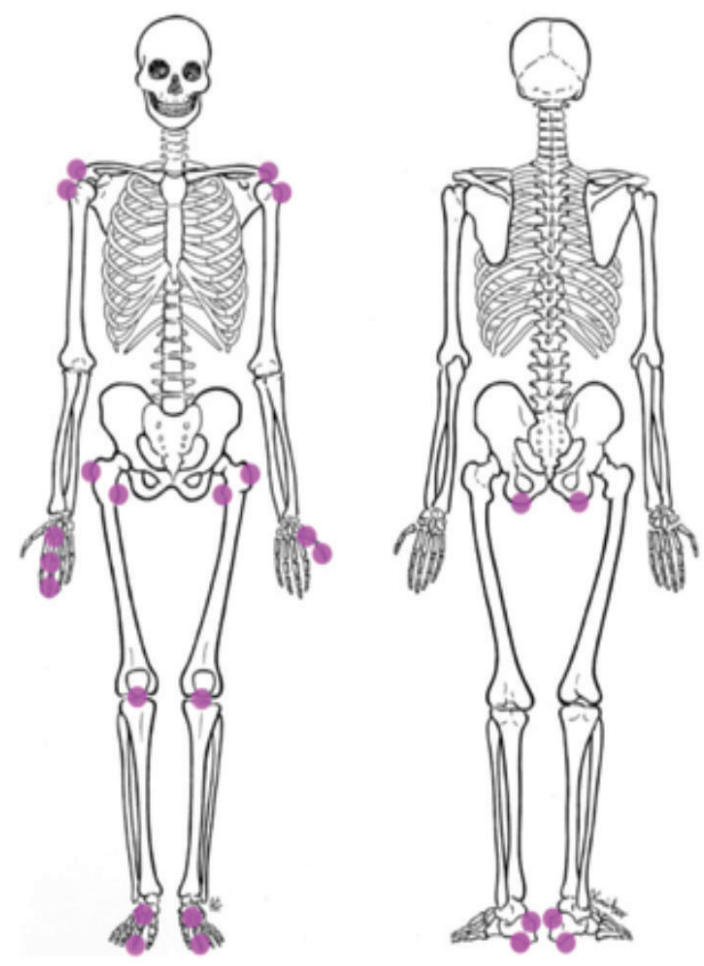

FIGURE 5: Most commonly affected appendicular entheseal sites in spondyloarthritis (Reprinted (with minor modification) from Eshed et al., 2007 [114], with permission, copyright ( $~ 2007$, BMJ Publishing Group Ltd.)

\section{Perspectives}

Understanding the mechanism of molecules in test tube is the first key step. Functional approach then can be better understood using the in vivo methods especially if genetic altered models are available and through knockdown approaches, availability of genetic variants predisposition to injury, and genes involved in human genetic diseases data. Proteoglycans and glycoproteins are part of tendon, ligament, and enthesis. Dry mass of tendon contains $1 \%-5 \%$ proteoglycans. This review has provided the functional importance of each molecule in tendon, ligament, or enthesis. Understanding these genes represents drug targets for disrupting pathological mechanisms that lead to tendinopathy, ligamentopathy, enthesopathy, enthesitis and tendon/ligament injury, that is, osteoarthritis.

Spondyloarthritis (SpA) refers to a group of HLA-B27positive associated rheumatic diseases that share clinical and genetic features [167]. The diseases and conditions that constitute the SpA group are defined by signs, symptoms, and radiographic findings and are consisted of ankylosing spondylitis (AS), reactive arthritis, psoriatic arthritis, Crohn's disease, ulcerative colitis, and a subgroup of undifferentiated forms $[168,169]$. The main clinical feature of SpA is inflammation of the axial spine. Articular, periarticular, and extra-articular manifestations also occur, depending on the type of SpA. Spondyloarthritis is a major health challenge given the propensity to affect young adults and the potential requirement for life-long treatment [170].

A number of genes in this review have addressed the importance of proteoglycans and glycoproteins in joints in response to alteration in ligaments/tendon and hence via entheses. Abnormalities in entheses can lead to enthesitis. Inflammation at the entheses, the sites of attachment of tendon, ligament, fascia, or joint capsule to bone, is the distinguishing pathological feature of AS and the other SpA [171-173]. Ankylosing spondylitis is considered as a disease continuum with symptoms depending on age at onset and the important manifestation in the early stage of disease is not inflammatory back pain but peripheral arthritis and enthesitis [174]. Entheses are numerous and present everywhere, both in the axial and appendicular skeleton, explaining the wide clinical spectrum of enthesitis. Enthesitis can involve (a) synovial joints such as the sacroiliac joints, the zygaphophyseal joints, the hips, the shoulders, and the knees; (b) fibrocartilaginous joints such as the pubic symphysis, the intervertebral symphysis joint; (c) syndesmoses such as the interosseus sacroiliac ligament filling the irregular space posterosuperior to the sacroiliac joint; (d) extra-articular entheses [175]. The most commonly affected appendicular entheseal sites in SpA are shown in Figure 5 [114].

Excellent review has been published on a large number of gene variants involved in SpA and AS $[170,176]$. Which genes are the cause and which are the effect still remains challenge in understanding the disease.

\section{Abbreviations}

BMP: BMPR2:

Col3al:

CACP:

Bone morphogenetic protein

Dbl-KO:

E:

ECM:

EDS:

FDL:

GAG:

IHC: Bone morphogenetic protein receptor, type II

Insertion (IGD): Insertion, intragenic deletion

ISH: In situ hybridization

Loc: Location

LRR: $\quad$ Leucine-rich repeat

LRRNT: $\quad$ LRR containing N-terminal domain

Mut:

OA: Mutation

P: Postnatal day

PDGFb: $\quad$ Platelet-derived growth factor $\beta$

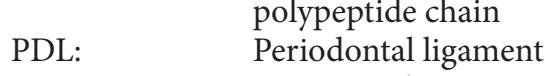

SEM: $\quad$ Scanning electron microscopy

SLRP: $\quad$ Small leucine-rich proteoglycan

Syn: Synonym 
$\mathrm{T}(\mathrm{KO})$ : Targeted (knockout)

$\mathrm{T}(\mathrm{KI})$ : Targeted (knockin)

T (R): $\quad$ Targeted (reporter)

TEM: Transmission electron microscopy

Tgf $\beta$ : Transforming growth factor beta

tml: $\quad$ Targeted mutation 1

WT: Wild type (control mouse)

N/A: Phenotype not available, that is, phenotype not studied by the authors in that reference paper.

\section{Conflict of Interests}

The authors declare that they have no conflict of interests.

\section{Acknowledgments}

Thanks are due to Professors Dr. Archibald Perkins and Prof. Dr. Regis O'Keefe for providing the authors with the best training in tendon and arthritis research.

\section{References}

[1] J. H. Yoon and J. Halper, "Tendon proteoglycans: biochemistry and function," Journal of Musculoskeletal Neuronal Interactions, vol. 5, no. 1, pp. 22-34, 2005.

[2] A. Malmström, B. Bartolini, M. A. Thelin, B. Pacheco, and M. Maccarana, "Iduronic acid in chondroitin/dermatan sulfate: biosynthesis and biological function," Journal of Histochemistry \& Cytochemistry, vol. 60, pp. 916-925, 2012.

[3] L. W. Ruddock and M. Molinari, "N-glycan processing in ER quality control," Journal of Cell Science, vol. 119, no. 21, pp. 43734380, 2006.

[4] P. Kannus, "Structure of the tendon connective tissue," Scandinavian Journal of Medicine and Science in Sports, vol. 10, no. 6, pp. 312-320, 2000.

[5] L. Jozsa and P. Kannus, Eds., Human Tendons: Anatomy, Physiology, and Pathology, Human Kinetics, Champaign, III, USA, 1997.

[6] S. Fukuta, M. Oyama, K. Kavalkovich, F. H. Fu, and C. Niyibizi, "Identification of types II, IX and X collagens at the insertion site of the bovine Achilles tendon," Matrix Biology, vol. 17, no. 1, pp. 65-73, 1998.

[7] C. M. McNeilly, A. J. Banes, M. Benjamin, and J. R. Ralphs, "Tendon cells in vivo form a three dimensional network of cell processes linked by gap junctions," Journal of Anatomy, vol. 189, no. 3, pp. 593-600, 1996.

[8] M. Benjamin and D. McGonagle, "Entheses: tendon and ligament attachment sites," Scandinavian Journal of Medicine and Science in Sports, vol. 19, no. 4, pp. 520-527, 2009.

[9] M. P. G. Bostrom, A. Boskey, J. K. Kauffman, and T. A. Einhorn, "Form and function of bone," in Orthopaedic Basic Science, J. A. Buckwalter, T. A. Einhorn, and S. R. Simon, Eds., pp. 319-370, AAOS, Rosement, Ill, USA, 2000.

[10] S. L. Woo, K. An, C. B. Frank et al., "Anatomy, biology, and biomechanics of tendon and ligament," in Orthopaedic Basic Science, J. A. Buckwalter, T. A. Einhorn, and S. R. Simon, Eds., pp. 581-616, AAOS, Rosement, Ill, USA, 2000.

[11] R. M. Jones, Mechanics of Composite Materials, Taylor \& Francis, Philadelphia, Pa, USA, 1999.
[12] S. Thomopoulos, G. M. Genin, and L. M. Galatz, “The development and morphogenesis of the tendon-to-bone insertionwhat development can teach us about healing," Journal of Musculoskeletal Neuronal Interactions, vol. 10, no. 1, pp. 35-45, 2010.

[13] M. Benjamin and J. R. Ralphs, "Fibrocartilage in tendons and ligaments - an adaptation to compressive load," Journal of Anatomy, vol. 193, no. 4, pp. 481-494, 1998.

[14] M. R. Capecchi, “Targeted gene replacement," Scientific American, vol. 270, no. 3, pp. 52-59, 1994.

[15] F. Recillas-Targa, "Multiple strategies for gene transfer, expression, knockdown, and chromatin influence in mammalian cell lines and transgenic animals," Molecular Biotechnology, vol. 34, no. 3, pp. 337-354, 2006.

[16] C. R. Scriver, A. L. Beaudet, W. S. Sly, and D. Valle, Eds., The Metabolic \& Molecular Bases of Inherited Disease, vol. 1-4, McGraw-Hill, New York, NY, USA, 8th edition, 2001.

[17] H. Lango and M. N. Weedon, "What will whole genome searches for susceptibility genes for common complex disease offer to clinical practice?" Journal of Internal Medicine, vol. 263, no. 1, pp. 16-27, 2008.

[18] L. Schaefer and R. V. Iozzo, "Biological functions of the small leucine-rich proteoglycans: from genetics to signal transduction," Journal of Biological Chemistry, vol. 283, no. 31, pp. 2130521309, 2008.

[19] S. Chakravarti, R. L. Stallings, N. SundarRaj, P. K. Cornuet, and J. R. Hassell, "Primary structure of human lumican (keratan sulfate proteoglycan) and localization of the gene (LUM) to chromosome 12q21.3-q22," Genomics, vol. 27, no. 3, pp. 481-488, 1995.

[20] S. Chakravarti, T. Magnuson, J. H. Lass, K. J. Jepsen, C. LaMantia, and H. Carroll, "Lumican regulates collagen fibril assembly: skin fragility and corneal opacity in the absence of lumican," Journal of Cell Biology, vol. 141, no. 5, pp. 1277-1286, 1998.

[21] R. V. Iozzo, "The biology of the small leucine-rich proteoglycans. Functional network of interactive proteins," Journal of Biological Chemistry, vol. 274, no. 27, pp. 18843-18846, 1999.

[22] A.-M. K. Säämänen, H. J. Salminen, A. J. Rantakokko, D. Heinegård, and E. I. Vuorio, "Murine fibromodulin: cDNA and genomic structure, and age-related expression and distribution in the knee joint," Biochemical Journal, vol. 355, no. 3, pp. 577$585,2001$.

[23] M. V. Nurminskaya and D. E. Birk, "Differential expression of fibromodulin mRNA associated with tendon fibril growth: isolation and characterization of a chicken fibromodulin cDNA," Biochemical Journal, vol. 317, no. 3, pp. 785-789, 1996.

[24] S. Kalamajski and Å. Oldberg, "Fibromodulin binds collagen type I via Glu-353 and Lys-355 in leucine-rich repeat 11," Journal of Biological Chemistry, vol. 282, no. 37, pp. 26740-26745, 2007.

[25] S. Kalamajski and Å. Oldberg, "Homologous sequence in Lumican and fibromodulin leucine-rich repeat 5-7 competes for collagen binding," Journal of Biological Chemistry, vol. 284, no. 1, pp. 534-539, 2009.

[26] Y. Ezura, S. Chakravarti, A. Oldberg, I. Chervoneva, and D. E. Birk, "Differential expression of lumican and fibromodulin regulate collagen fibrillogenesis in developing mouse tendons," Journal of Cell Biology, vol. 151, no. 4, pp. 779-788, 2000.

[27] L. Svensson, A. Aszódi, F. P. Reinholt, R. Fässler, D. Heinegård, and Å. Oldberg, "Fibromodulin-null mice have abnormal collagen fibrils, tissue organization, and altered lumican deposition 
in tendon," Journal of Biological Chemistry, vol. 274, no. 14, pp. 9636-9647, 1999.

[28] K. J. Jepsen, F. Wu, J. H. Peragallo et al., "A syndrome of joint laxity and impaired tendon integrity in lumican- and fibromodulin-deficient mice," Journal of Biological Chemistry, vol. 277, no. 38, pp. 35532-35540, 2002.

[29] S. Kalamajski and A. Oldberg, "The role of small leucine-rich proteoglycans in collagen fibrillogenesis," Matrix Biology, vol. 29, no. 4, pp. 248-253, 2010.

[30] E. Schönherr, H. Hausser, L. Beavan, and H. Kresse, "Decorintype I collagen interaction. Presence of separate core proteinbinding domains," Journal of Biological Chemistry, vol. 270, no. 15, pp. 8877-8883, 1995.

[31] C. Wiberg, E. Hedbom, A. Khairullina et al., "Biglycan and decorin bind close to the N-terminal region of the collagen VI triple helix," Journal of Biological Chemistry, vol. 276, no. 22, pp. 18947-18952, 2001.

[32] C. Wiberg, A. R. Klatt, R. Wagener et al., "Complexes of matrilin-1 and biglycan or decorin connect collagen VI microfibrils to both collagen II and aggrecan," Journal of Biological Chemistry, vol. 278, no. 39, pp. 37698-37704, 2003.

[33] G. Zhang, Y. Ezura, I. Chervoneva et al., "Decorin regulates assembly of collagen fibrils and acquisition of biomechanical properties during tendon development," Journal of Cellular Biochemistry, vol. 98, no. 6, pp. 1436-1449, 2006.

[34] J. R. Robbins, S. P. Evanko, and K. G. Vogel, "Mechanical loading and TGF- $\beta$ regulate proteoglycan synthesis in tendon," Archives of Biochemistry and Biophysics, vol. 342, no. 2, pp. 203-211, 1997.

[35] K. G. Danielson, H. Baribault, D. F. Holmes, H. Graham, K. E. Kadler, and R. V. Iozzo, "Targeted disruption of decorin leads to abnormal collagen fibril morphology and skin fragility," Journal of Cell Biology, vol. 136, no. 3, pp. 729-743, 1997.

[36] A. Corsi, T. Xu, X.-D. Chen et al., "Phenotypic effects of biglycan deficiency are linked to collagen fibril abnormalities, are synergized by decorin deficiency, and mimic Ehlers-Danloslike changes in bone and other connective tissues," Journal of Bone and Mineral Research, vol. 17, no. 7, pp. 1180-1189, 2002.

[37] L. Häkkinen, S. Strassburger, V.-M. Kähäri et al., "A role for decorin in the structural organization of periodontal ligament," Laboratory Investigation, vol. 80, no. 12, pp. 1869-1880, 2000.

[38] L. M. Dourte, L. Pathmanathan, A. F. Jawad et al., "Influence of decorin on the mechanical, compositional, and structural properties of the mouse patellar tendon," Journal of Biomechanical Engineering, vol. 134, no. 3, Article ID 031005, 2012.

[39] S. Ilkhani-Pour, P. B. Voleti, M. R. Buckley et al., "Achilles tendon repair response to injury is enhanced by the absence of decorin," in Proceedings of the Orthopedic Research Society Annual Meeting, San Antonio, Tex, USA, January 2013.

[40] M. Maccarana, S. Kalamajski, M. Kongsgaard, S. Peter Magnusson, Å. Oldberg, and A. Malmström, "Dermatan sulfate epimerase 1-deficient mice have reduced content and changed distribution of iduronic acids in dermatan sulfate and an altered collagen structure in skin," Molecular and Cellular Biology, vol. 29, no. 20, pp. 5517-5528, 2009.

[41] S. Matheson, H. Larjava, and L. Häkkinen, "Distinctive localization and function for lumican, fibromodulin and decorin to regulate collagen fibril organization in periodontal tissues," Journal of Periodontal Research, vol. 40, no. 4, pp. 312-324, 2005.

[42] D. M. Elliott, P. S. Robinson, J. A. Gimbel et al., "Effect of altered matrix proteins on quasilinear viscoelastic properties in transgenic mouse tail tendons," Annals of Biomedical Engineering, vol. 31, no. 5, pp. 599-605, 2003.
[43] A. Schnieke, K. Harbers, and R. Jaenisch, "Embryonic lethal mutation in mice induced by retrovirus insertion into the $\alpha 1$ (I) collagen gene," Nature, vol. 304, no. 5924, pp. 315-320, 1983.

[44] K. Harbers, M. Kuehn, H. Delius, and R. Jaenisch, "Insertion of retrovirus into the first intron of $\alpha 1$ (I) collagen gene leads to embryonic lethal mutation in mice," Proceedings of the National Academy of Sciences of the United States of America, vol. 20, no. 1, pp. 1504-1508, 1984.

[45] J. Bonadio, T. L. Saunders, E. Tsai et al., "Transgenic mouse model of the mild dominant form of osteogenesis imperfecta," Proceedings of the National Academy of Sciences of the United States of America, vol. 87, no. 18, pp. 7145-7149, 1990.

[46] P. S. Robinson, T. W. Lin, P. R. Reynolds, K. A. Derwin, R. V. Iozzo, and L. J. Soslowsky, "Strain-Rate Sensitive Mechanical Properties of Tendon Fascicles from Mice with Genetically Engineered Alterations in Collagen and Decorin," Journal of Biomechanical Engineering, vol. 126, no. 2, pp. 252-257, 2004.

[47] X. Liu, H. Wu, M. Byrne, J. Jeffrey, S. Krane, and R. Jaenisch, "A targeted mutation at the known collagenase cleavage site in mouse type I collagen impairs tissue remodeling," Journal of Cell Biology, vol. 130, no. 1, pp. 227-237, 1995.

[48] P. S. Robinson, T. W. Lin, A. F. Jawad, R. V. Iozzo, and L. J. Soslowsky, "Investigating tendon fascicle structure-function relationships in a transgenic-age mouse model using multiple regression models," Annals of Biomedical Engineering, vol. 32, no. 7, pp. 924-931, 2004.

[49] T. Xu, P. Bianco, L. W. Fisher et al., "Targeted disruption of the biglycan gene leads to an osteoporosis-like phenotype in mice," Nature Genetics, vol. 20, no. 1, pp. 78-82, 1998.

[50] Y. Hiroyuki, F. Hiromichi, A. Wataru, and N. Norimasa, "Patellar tendon strength of a specific protein-knockout mouse. Effects of biglycan on the mechanical property of biological fibrous tissues," Nihon Kikai Gakkai Kanto Shibu Sokai Koen Ronbunshu, vol. 11, pp. 475-476, 2005.

[51] R. Chiu, W. Li, R. P. Herber, S. J. Marshall, M. Young, and S. P. Ho, "Effects of biglycan on physico-chemical properties of ligament-mineralized tissue attachment sites," Archives of Oral Biology, vol. 57, no. 2, pp. 177-187, 2012.

[52] L. Ameye, D. Aria, K. Jepsen, A. K. E. Oldberg, T. Xu, and M. F. Young, "Abnormal collagen fibrils in tendons of biglycan/fibromodulin-deficient mice lead to gait impairment, ectopic ossification, and osteoarthritis," FASEB Journal, vol. 16, no. 7, pp. 673-680, 2002.

[53] Y. Bi, D. Ehirchiou, T. M. Kilts et al., "Identification of tendon stem/progenitor cells and the role of the extracellular matrix in their niche," Nature Medicine, vol. 13, no. 10, pp. 1219-1227, 2007.

[54] T. Kilts, L. Ameye, F. Syed-Picard et al., "Potential roles for the small leucine-rich proteoglycans biglycan and fibromodulin in ectopic ossification of tendon induced by exercise and in modulating rotarod performance," Scandinavian Journal of Medicine and Science in Sports, vol. 19, no. 4, pp. 536-546, 2009.

[55] P. S. Robinson, T.-F. Huang, E. Kazam, R. V. Iozzo, D. E. Birk, and L. J. Soslowsky, "Influence of decorin and biglycan on mechanical properties of multiple tendons in knockout mice," Journal of Biomechanical Engineering, vol. 127, no. 1, pp. 181-185, 2005.

[56] A. A. Dunkman, M. R. Buckley, M. J. Mienaltowski et al., "Decorin expression is important for age-related changes in tendon structure and mechanical properties," Matrix Biology, vol. 32, pp. 3-13, 2013. 
[57] B. K. Connizzo, J. J. Sarver, D. E. Birk, and L. J. Soslowsky, "Effect of age and proteoglycan deficiency on collagen fiber realignment and mechanical properties in mouse supraspinatus tendon," Journal of Biomechanical Engineering, vol. 135, no. 2, Article ID 021019, 2013.

[58] G. Zhang, S. Chen, S. Goldoni et al., "Genetic evidence for the coordinated regulation of collagen fibrillogenesis in the cornea by decorin and biglycan," Journal of Biological Chemistry, vol. 284, no. 13, pp. 8888-8897, 2009.

[59] M. Nakajima, H. Kizawa, M. Saitoh, I. Kou, K. Miyazono, and S. Ikegawa, "Mechanisms for asporin function and regulation in articular cartilage," Journal of Biological Chemistry, vol. 282, no. 44, pp. 32185-32192, 2007.

[60] M. Tomoeda, S. Yamada, H. Shirai, Y. Ozawa, M. Yanagita, and S. Murakami, "PLAP-1/asporin inhibits activation of BMP receptor via its leucine-rich repeat motif," Biochemical and Biophysical Research Communications, vol. 371, no. 2, pp. 191196, 2008.

[61] S. Kalamajski, A. Aspberg, K. Lindblom, D. Heinegård, and Å. Oldberg, "Asporin competes with decorin for collagen binding, binds calcium and promotes osteoblast collagen mineralization," Biochemical Journal, vol. 423, no. 1, pp. 53-59, 2009.

[62] S. Yamada, M. Tomoeda, Y. Ozawa et al., "PLAP-1/asporin, a novel negative regulator of periodontal ligament mineralization," Journal of Biological Chemistry, vol. 282, no. 32, pp. 2307023080, 2007.

[63] I. Kou, M. Nakajima, and S. Ikegawa, "Expression and regulation of the osteoarthritis-associated protein asporin," Journal of Biological Chemistry, vol. 282, no. 44, pp. 32193-32199, 2007.

[64] S. P. Henry, M. Takanosu, T. C. Boyd et al., "Expression pattern and gene characterization of asporin. A newly discovered member of the leucine-rich repeat protein family," Journal of Biological Chemistry, vol. 276, no. 15, pp. 12212-12221, 2001.

[65] C. Li, C. Li, J. Yue et al., "miR-21 and miR-101 regulate PLAP1 expression in periodontal ligament cells," Molecular Medicine Reports, vol. 5, no. 5, pp. 1340-1346, 2012.

[66] M. W. M. Schellings, Y. M. Pinto, and S. Heymans, "Matricellular proteins in the heart: possible role during stress and remodeling," Cardiovascular Research, vol. 64, no. 1, pp. 24-31, 2004.

[67] J. C. Adams, "Thrombospondins: multifunctional regulators of cell interactions," Annual Review of Cell and Developmental Biology, vol. 17, pp. 25-51, 2001.

[68] M. Koch, F. Hussein, A. Woeste et al., "CD36-mediated activation of endothelial cell apoptosis by an $\mathrm{N}$-terminal recombinant fragment of thrombospondin-2 inhibits breast cancer growth and metastasis in vivo," Breast Cancer Research and Treatment, vol. 128, no. 2, pp. 337-346, 2011.

[69] R. Simantov, M. Febbraio, and R. L. Silverstein, "The antiangiogenic effect of thrombospondin-2 is mediated by CD36 and modulated by histidine-rich glycoprotein," Matrix Biology, vol. 24, no. 1, pp. 27-34, 2005.

[70] A. S. Asch, S. Silbiger, E. Heimer, and R. L. Nachman, "Thrombospondin sequence motif (CSVTCG) is responsible for CD36 binding," Biochemical and Biophysical Research Communications, vol. 182, no. 3, pp. 1208-1217, 1992.

[71] T. M. Misenheimer, A. J. Hahr, A. C. Harms, D. S. Annis, and D. F. Mosher, "Disulfide connectivity of recombinant C-terminal region of human thrombospondin 2," Journal of Biological Chemistry, vol. 276, no. 49, pp. 45882-45887, 2001.
[72] C. B. Carlson, D. A. Bernstein, D. S. Annis et al., "Structure of the calcium-rich signature domain of human thrombospondin2," Nature Structural and Molecular Biology, vol. 12, no. 10, pp. 910-914, 2005.

[73] H. Chen, J. Sottile, K. M. O’Rourke, V. M. Dixit, and D. F. Mosher, "Properties of recombinant mouse thrombospondin 2 expressed in Spodoptera cells," Journal of Biological Chemistry, vol. 269, no. 51, pp. 32226-32232, 1994.

[74] H. Chen, D. K. Strickland, and D. F. Mosher, "Metabolism of thrombospondin 2: binding and degradation by $3 \mathrm{~T} 3$ cells and glycosaminoglycan-variant Chinese hamster ovary cells," Journal of Biological Chemistry, vol. 271, no. 27, pp. 15993-15999, 1996.

[75] M. L. Iruela-Arispe, D. J. Liska, E. H. Sage, and P. Bornstein, "Differential expression of thrombospondin 1,2, and 3 during murine development," Developmental Dynamics, vol. 197, no. 1, pp. 40-56, 1993.

[76] R. P. Tucker, J. C. Adams, and J. Lawler, "Thrombospondin-4 is expressed by early osteogenic tissues in the chick embryo," Developmental Dynamics, vol. 203, no. 4, pp. 477-490, 1995.

[77] T. R. Kyriakides, Y.-H. Zhu, L. T. Smith et al., "Mice that lack thrombospondin 2 display connective tissue abnormalities that are associated with disordered collagen fibrillogenesis, an increased vascular density, and a bleeding diathesis," Journal of Cell Biology, vol. 140, no. 2, pp. 419-430, 1998.

[78] P. Bornstein, T. R. Kyriakides, Z. Yang, L. C. Armstrong, and D. E. Birk, "Thrombospondin 2 modulates collagen fibrillogenesis and angiogenesis," Journal of Investigative Dermatology Symposium Proceedings, vol. 5, no. 1, pp. 61-66, 2000.

[79] R. Zohar, W. Lee, P. Arora, S. Cheifetz, C. McCulloch, and J. Sodek, "Single cell analysis of intracellular osteopontin in osteogenic cultures of fetal rat calvarial cells," Journal of Cellular Physiology, vol. 170, no. 1, pp. 88-100, 1997.

[80] B. Christensen, M. S. Nielsen, K. F. Haselmann, T. E. Petersen, and E. S. Sørensen, "Post-translationally modified residues of native human osteopontin are located in clusters: identification of 36 phosphorylation and five O-glycosylation sites and their biological implications," Biochemical Journal, vol. 390, no. 1, pp. 285-292, 2005.

[81] V. S. Tagliabracci, J. L. Engel, J. Wen et al., "Secreted kinase phosphorylates extracellular proteins that regulate biomineralization," Science, vol. 336, no. 6085, pp. 1150-1153, 2012.

[82] E. S. Sorensen, P. Hojrup, and T. E. Petersen, "Posttranslational modifications of bovine osteopontin: identification of twentyeight phosphorylation and three O-glycosylation sites," Protein Science, vol. 4, no. 10, pp. 2040-2049, 1995.

[83] D. T. Denhardt, M. Noda, A. W. O’Regan, D. Pavlin, and J. S. Berman, "Osteopontin as a means to cope with environmental insults: regulation of inflammation, tissue remodeling, and cell survival," Journal of Clinical Investigation, vol. 107, no. 9, pp. 1055-1061, 2001.

[84] S. Ashkar, G. F. Weber, V. Panoutsakopoulou et al., "Eta-1 (osteopontin): an early component of type-1 (cell-mediated) immunity," Science, vol. 287, no. 5454, pp. 860-864, 2000.

[85] N. Mori, T. Majima, N. Iwasaki et al., "The role of osteopontin in tendon tissue remodeling after denervation-induced mechanical stress deprivation," Matrix Biology, vol. 26, no. 1, pp. 42-53, 2007.

[86] E. Takeuchi, K. Sugamoto, T. Nakase et al., "Localization and expression of osteopontin in the rotator cuff tendons in patients with calcifying tendinitis," Virchows Archiv, vol. 438, no. 6, pp. 612-617, 2001. 
[87] S. R. Rittling, H. N. Matsumoto, M. D. Mckee et al., "Mice lacking osteopontin show normal development and bone structure but display altered osteoclast formation in vitro," Journal of Bone and Mineral Research, vol. 13, no. 7, pp. 1101-1111, 1998.

[88] J. Engel, W. Taylor, M. Paulsson, H. Sage, and B. Hogan, "Calcium binding domains and calcium-induced conformational transition of SPARC/BM-40/osteonectin, an extracellular glycoprotein expressed in mineralized and nonmineralized tissues," Biochemistry, vol. 26, no. 22, pp. 6958-6965, 1987.

[89] S. McCurdy, C. F. Baicu, S. Heymans, and A. D. Bradshaw, "Cardiac extracellular matrix remodeling: fibrillar collagens and secreted protein Acidic and Rich in Cysteine (SPARC)," Journal of Molecular and Cellular Cardiology, vol. 48, no. 3, pp. 544-549, 2010.

[90] C. Giudici, N. Raynal, H. Wiedemann et al., "Mapping of SPARC/BM-40/osteonectin-binding sites on fibrillar collagens," Journal of Biological Chemistry, vol. 283, no. 28, pp. 1955119560, 2008.

[91] T. J. Rentz, F. Poobalarahi, P. Bornstein, E. H. Sage, and A. D. Bradshaw, "SPARC regulates processing of procollagen I and collagen fibrillogenesis in dermal fibroblasts," Journal of Biological Chemistry, vol. 282, no. 30, pp. 22062-22071, 2007.

[92] E. Van Der Zee, V. Everts, and W. Beertsen, "Cytokines modulate routes of collagen breakdown Review with special emphasis on mechanisms of collagen degradation in the periodontium and the burst hypothesis of periodontal disease progression," Journal of Clinical Periodontology, vol. 24, no. 5, pp. 297-305, 1997.

[93] J. S. Kinney, C. A. Ramseier, and W. V. Giannobile, "Oral fluidbased biomarkers of alveolar bone loss in periodontitis," Annals of the New York Academy of Sciences, vol. 1098, pp. 230-251, 2007.

[94] K. Norose, J. I. Clark, N. A. Syed et al., "SPARC deficiency leads to early-onset cataractogenesis," Investigative Ophthalmology and Visual Science, vol. 39, no. 13, pp. 2674-2680, 1998.

[95] J. M. Trombetta and A. D. Bradshaw, "SPARC/osteonectin functions to maintain homeostasis of the collagenous extracellular matrix in the periodontal ligament," Journal of Histochemistry and Cytochemistry, vol. 58, no. 10, pp. 871-879, 2010.

[96] J. Trombetta-Esilva, H. Yu, D. N. Arias, C. Rossa Jr., K. L. Kirkwood, and A. D. Bradshaw, "LPS induces greater bone and PDL loss in SPARC-null mice," Journal of Dental Research, vol. 90, no. 4, pp. 477-482, 2011.

[97] J. Trombetta-Esilva and A. D. Bradshaw, "The function of SPARC as a mediator of fibrosis," The Open Rheumatology Journal, vol. 6, pp. 146-155, 2012.

[98] J. Wilde, M. Yokozeki, K. Terai, A. Kudo, and K. Moriyama, “The divergent expression of periostin mRNA in the periodontal ligament during experimental tooth movement," Cell and Tissue Research, vol. 312, no. 3, pp. 345-351, 2003.

[99] D. W. Hamilton, "Functional role of periostin in development and wound repair: implications for connective tissue disease," Journal of Cell Communication and Signaling, vol. 2, no. 1-2, pp. 9-17, 2008.

[100] A. Kudo, "Periostin in fibrillogenesis for tissue regeneration: periostin actions inside and outside the cell," Cellular and Molecular Life Sciences, vol. 68, no. 19, pp. 3201-3207, 2011.

[101] H. Rios, S. V. Koushik, H. Wang et al., "periostin null mice exhibit dwarfism, incisor enamel defects, and an early-onset periodontal disease-like phenotype," Molecular and Cellular Biology, vol. 25, no. 24, pp. 11131-11144, 2005.
[102] I. Kii, N. Amizuka, L. Minqi, S. Kitajima, Y. Saga, and A. Kudo, "Periostin is an extracellular matrix protein required for eruption of incisors in mice," Biochemical and Biophysical Research Communications, vol. 342, no. 3, pp. 766-772, 2006.

[103] G. P. Riley, R. L. Harrall, T. E. Cawston, B. L. Hazleman, and E. J. Mackie, "Tenascin-C and human tendon degeneration," American Journal of Pathology, vol. 149, no. 3, pp. 933-943, 1996.

[104] H. Suzuki, N. Amizuka, I. Kii et al., "Immunohistochemical localization of periostin in tooth and its surrounding tissues in mouse mandibles during development," Anatomical Record A, vol. 281, no. 2, pp. 1264-1275, 2004.

[105] H. F. Rios, D. Ma, Y. Xie et al., "Periostin is essential for the integrity and function of the periodontal ligament during occlusal loading in mice," Journal of Periodontology, vol. 79, no. 8, pp. 1480-1490, 2008.

[106] D. Hakuno, N. Kimura, M. Yoshioka et al., "Periostin advances atherosclerotic and rheumatic cardiac valve degeneration by inducing angiogenesis and MMP production in humans and rodents," Journal of Clinical Investigation, vol. 120, no. 7, pp. 2292-2306, 2010.

[107] T. Oka, J. Xu, R. A. Kaiser et al., "Genetic manipulation of periostin expression reveals a role in cardiac hypertrophy and ventricular remodeling," Circulation Research, vol. 101, no. 3, pp. 313-321, 2007.

[108] R. A. Morris, B. Damon, V. Mironov et al., "Periostin regulates collagen fibrillogenesis and the biomechanical properties of connective tissues," Journal of Cellular Biochemistry, vol. 101, no. 3, pp. 695-711, 2007.

[109] C. S. Chamberlain, K. I. Rolnick, E. M. Leiferman, S. Liegel, G. S. Baer, and R. Vanderby, "Periostin deficient mouse tendons exhibit altered collagen patterns," in Proceedings of the Orthopedic Research Society Annual Meeting, San Antonio, Tex, USA, January 2013.

[110] R. Chiquet-Ehrismann and R. P. Tucker, "Tenascins and the importance of adhesion modulation," Cold Spring Harbor Perspectives in Biology, vol. 3, no. 5, 2011.

[111] F. Morellini and M. Schachner, "Enhanced novelty-induced activity, reduced anxiety, delayed resynchronization to daylight reversal and weaker muscle strength in tenascin-C-deficient mice," European Journal of Neuroscience, vol. 23, no. 5, pp. 12551268, 2006.

[112] S. C. Juneja, R. J. O’Keefe, E. M. Schwarz, and H. A. Awad, "Cellular and molecular interactions in flexor tendon repairs: towards regenerative scarless healing," in Proceedings of the Orthopedic Research Society Annual Meeting, pp. 4-7, Francisco, Calif, USA, February 2012.

[113] S. C. Juneja, "Cellular distribution and gene expression profile during flexor tendon graft repair: a novel tissue engineering approach," Journal of Tissue Engineering, vol. 4, 2013.

[114] I. Eshed, M. Bollow, D. G. McGonagle et al., "MRI of enthesitis of the appendicular skeleton in spondyloarthritis," Annals of the Rheumatic Diseases, vol. 66, no. 12, pp. 1553-1559, 2007.

[115] L. Jozsa, M. Kvist, B. J. Balint et al., "The role of recreational sport activity in Achilles tendon rupture. A clinical, pathoanatomical, and sociological study of 292 cases," American Journal of Sports Medicine, vol. 17, no. 3, pp. 338-343, 1989.

[116] E. J. Mackie, "Molecules in focus: tenascin-C", The International Journal of Biochemistry \& Cell Biology, vol. 29, pp. 1133-1137, 1997.

[117] M. Chiquet and D. M. Fambrough, "Chick myotendinous antigen. II. A novel extracellular glycoprotein complex consisting of 
large disulfide-linked subunits," Journal of Cell Biology, vol. 98, no. 6, pp. 1937-1946, 1984.

[118] T. A. H. Järvinen, L. Jozsa, P. Kannus et al., "Mechanical loading regulates tenascin- $\mathrm{C}$ expression in the osteotendinous junction," Journal of Cell Science, vol. 112, no. 18, pp. 3157-3166, 1999.

[119] T. A. H. Järvinen, L. Józsa, P. Kannus et al., "Mechanical loading regulates the expression of tenascin- $\mathrm{C}$ in the myotendinous junction and tendon but does not induce de novo synthesis in the skeletal muscle," Journal of Cell Science, vol. 116, no. 5, pp. 857-866, 2003.

[120] P. L. Jones and F. S. Jones, "Tenascin-C in development and disease: gene regulation and cell function," Matrix Biology, vol. 19, no. 7, pp. 581-596, 2000.

[121] F. T. Bosman and I. Stamenkovic, "Functional structure and composition of the extracellular matrix," Journal of Pathology, vol. 200, no. 4, pp. 423-428, 2003.

[122] D. Ireland, R. Harrall, V. Curry et al., "Multiple changes in gene expression in chronic human Achilles tendinopathy," Matrix Biology, vol. 20, no. 3, pp. 159-169, 2001.

[123] C. J. Saunders, L. van der Merwe, M. Posthumus et al., "Investigation of variants within the COL27A1 and TNC genes and Achilles tendinopathy in two populations," Journal of Orthopaedic Research, vol. 31, pp. 632-637, 2013.

[124] G. G. Mokone, M. Gajjar, A. V. September et al., "The guanine-thymine dinucleotide repeat polymorphism within the tenascin-C gene is associated with Achilles tendon injuries," American Journal of Sports Medicine, vol. 33, no. 7, pp. 1016-1021, 2005.

[125] K. Yagishita, I. Sekiya, Y. Sakaguchi, K. Shinomiya, and T. Muneta, "The effect of hyaluronan on tendon healing in rabbits," Arthroscopy, vol. 21, no. 11, pp. 1330-1336, 2005.

[126] D. Egging, F. Van Den Berkmortel, G. Taylor, J. Bristow, and J. Schalkwijk, "Interactions of human tenascin-X domains with dermal extracellular matrix molecules," Archives of Dermatological Research, vol. 298, no. 8, pp. 389-396, 2007.

[127] J. R. Mao, G. Taylor, W. B. Dean et al., "Tenascin-X deficiency mimics Ehlers-Danlos syndrome in mice through alteration of collagen deposition," Nature Genetics, vol. 30, no. 4, pp. 421-425, 2002.

[128] P. A. Huijing, N. C. Voermans, G. C. Baan, T. E. Busé, B. G. M. Van Engelen, and A. De Haan, "Muscle characteristics and altered myofascial force transmission in tenascin-X-deficient mice, a mouse model of Ehlers-Danlos syndrome," Journal of Applied Physiology, vol. 109, no. 4, pp. 986-995, 2010.

[129] O. Brandau, A. Meindl, R. Fässler, and A. Aszódi, "A novel gene, tendin, is strongly expressed in tendons and ligaments and shows high homology with chondromodulin-I," Developmental Dynamics, vol. 221, pp. 72-80, 2001.

[130] K. Yamana, H. Wada, Y. Takahashi, H. Sato, Y. Kasahara, and M. Kiyoki, "Molecular cloning and characterization of ChM1L, a novel membrane molecule similar to chondromodulin-I," Biochemical and Biophysical Research Communications, vol. 280, no. 4, pp. 1101-1106, 2001.

[131] P. J. Neame, J. T. Treep, and C. N. Young, "An 18-kDa glycoprotein from bovine nasal cartilage. Isolation and primary structure of small, cartilage-derived glycoprotein," Journal of Biological Chemistry, vol. 265, no. 17, pp. 9628-9633, 1990.

[132] Y. Hiraki, H. Tanaka, H. Inoue, J. Kondo, A. Kamizono, and F. Suzuki, "Molecular cloning of a new class of cartilagespecific matrix, chondromodulin-I, which stimulates growth of cultured chondrocytes," Biochemical and Biophysical Research Communications, vol. 175, no. 3, pp. 971-977, 1991.

[133] L. Sánchez-Pulido, D. Devos, and A. Valencia, "BRICHOS: a conserved domain in proteins associated with dementia, respiratory distress and cancer," Trends in Biochemical Sciences, vol. 27, no. 7, pp. 329-332, 2002.

[134] Y. Oshima, C. Shukunami, J. Honda et al., "Expression and localization of tenomodulin, a transmembrane type chondromodulin-I-related angiogenesis inhibitor, in mouse eyes," Investigative Ophthalmology and Visual Science, vol. 44, no. 5, pp. 1814-1823, 2003.

[135] Y. Oshima, K. Sato, F. Tashiro et al., "Anti-angiogenic action of the C-terminal domain of tenomodulin that shares homology with chondromodulin-I," Journal of Cell Science, vol. 117, no. 13, pp. 2731-2744, 2004.

[136] D. Docheva, E. B. Hunziker, R. Fässler, and O. Brandau, "Tenomodulin is necessary for tenocyte proliferation and tendon maturation," Molecular and Cellular Biology, vol. 25, no. 2, pp. 699-705, 2005.

[137] O. Brandau, A. Aszódi, E. B. Hunziker, P. J. Neame, D. Vestweber, and R. Fässler, "Chondromodulin I is dispensable during enchondral ossification and eye development," Molecular and Cellular Biology, vol. 22, no. 18, pp. 6627-6635, 2002.

[138] J. Qi, J. M. Dmochowski, A. N. Banes et al., "Differential expression and cellular localization of novel isoforms of the tendon biomarker tenomodulin," Journal of Applied Physiology, vol. 113, pp. 861-871, 2012.

[139] C. Shukunami, A. Takimoto, M. Oro, and Y. Hiraki, "Scleraxis positively regulates the expression of tenomodulin, a differentiation marker of tenocytes," Developmental Biology, vol. 298, no. 1, pp. 234-247, 2006.

[140] R. Schmits, J. Filmus, N. Gerwin et al., "CD44 regulates hematopoietic progenitor distribution, granuloma formation, and tumorigenicity," Blood, vol. 90, no. 6, pp. 2217-2233, 1997.

[141] H. L. Ansorge, P. K. Beredjiklian, and L. J. Soslowsky, "CD44 deficiency improves healing tendon mechanics and increases matrix and cytokine expression in a mouse patellar tendon injury model," Journal of Orthopaedic Research, vol. 27, no. 10, pp. 1386-1391, 2009.

[142] A. M. Malfait, J. Ritchie, A. S. Gil et al., "ADAMTS-5 deficient mice do not develop mechanical allodynia associated with osteoarthritis following medial meniscal destabilization," Osteoarthritis and Cartilage, vol. 18, no. 4, pp. 572-580, 2010.

[143] V. M. Wang, R. M. Bell, R. Thakore et al., "Murine tendon function is adversely affected by aggrecan accumulation due to the knockout of ADAMTS5," Journal of Orthopaedic Research, vol. 30, no. 4, pp. 620-626, 2012.

[144] D. K. Rhee, J. Marcelino, M. Baker et al., "The secreted glycoprotein lubricin protects cartilage surfaces and inhibits synovial cell overgrowth," Journal of Clinical Investigation, vol. 115, no. 3, pp. 622-631, 2005.

[145] R. T. Kohrs, C. Zhao, Y.-L. Sun et al., "Tendon fascicle gliding in wild type, heterozygous, and lubricin knockout mice," Journal of Orthopaedic Research, vol. 29, no. 3, pp. 384-389, 2011.

[146] J. Reuvers, A. R. Thoreson, C. Zhao et al., "The mechanical properties of tail tendon fascicles from lubricin knockout, wild type and heterozygous mice," Journal of Structural Biology, vol. 176, no. 1, pp. 41-45, 2011.

[147] T. Ochi, R. Iwase, and N. Okabe, "The pathology of the involved tendons in patients with familial arthropathy and congenital camptodactyly," Arthritis and Rheumatism, vol. 26, no. 7, pp. 896-900, 1983. 
[148] J. Marcelino, J. D. Carpten, W. M. Suwairi et al., "CACP, encoding a secreted proteoglycan, is mutated in camptodactylyarthropathy-coxa vara-pericarditis syndrome," Nature Genetics, vol. 23, no. 3, pp. 319-322, 1999.

[149] S. Basit, Z. Iqbal, M. Umicevic-Mirkov et al., "A novel deletion mutation in proteoglycan-4 underlies camptodactylyarthropathy-coxa-vara-pericarditis syndrome in a consanguineous pakistani family," Archives of Medical Research, vol. 42, no. 2, pp. 110-114, 2011.

[150] S. Goodison, V. Urquidi, and D. Tarin, "CD44 cell adhesion molecules," Journal of Clinical Pathology, vol. 52, no. 4, pp. 189196, 1999.

[151] A. Aruffo, I. Stamenkovic, M. Melnick, C. B. Underhill, and B. Seed, "CD44 is the principal cell surface receptor for hyaluronate," Cell, vol. 61, no. 7, pp. 1303-1313, 1990.

[152] M. Berglund, D. A. Hart, and M. Wiig, "The inflammatory response and hyaluronan synthases in the rabbit flexor tendon and tendon sheath following injury," Journal of Hand Surgery. European Volume, vol. 32, no. 5, pp. 581-587, 2007.

[153] M. Favata, P. K. Beredjiklian, M. H. Zgonis et al., "Regenerative properties of fetal sheep tendon are not adversely affected by transplantation into an adult environment," Journal of Orthopaedic Research, vol. 24, no. 11, pp. 2124-2132, 2006.

[154] S. Porter, I. M. Clark, L. Kevorkian, and D. R. Edwards, "The ADMTS metalloproteinases," Biochemical Journal, vol. 386, no. 1, pp. 15-27, 2005.

[155] A. D. Waggett, J. R. Ralphs, A. P. L. Kwan, D. Woodnutt, and M. Benjamin, "Characterization of collagens and proteoglycans at the insertion of the human Achilles tendon," Matrix Biology, vol. 16, no. 8, pp. 457-470, 1998.

[156] K. G. Vogel, J. D. Sandy, G. Pogany, and J. R. Robbins, "Aggrecan in bovine tendon," Matrix Biology, vol. 14, no. 2, pp. 171-179, 1994.

[157] A. Plaas, J. D. Sandy, H. Liu et al., "Biochemical identification and immunolocalizaton of aggrecan, ADAMTS5 and interalpha-trypsin-inhibitor in equine degenerative suspensory ligament desmitis," Journal of Orthopaedic Research, vol. 29, no. 6, pp. 900-906, 2011.

[158] K. A. Waller, L. X. Zhang, K. A. Elsaid, B. C. Fleming, M. L. Warman, and G. D. Jay, "Role of lubricin and boundary lubrication in the prevention of chondrocyte apoptosis," Proceedings of the National Academy of Sciences of the United States of America, vol. 110, pp. 5852-5857, 2013.

[159] D. K. Rhee, J. Marcelino, S. Al-Mayou et al., "Consequences of disease-causing mutations on lubricin protein synthesis, secretion, and post-translational processing," Journal of Biological Chemistry, vol. 280, no. 35, pp. 31325-31332, 2005.

[160] S. Ikegawa, M. Sano, Y. Koshizuka, and Y. Nakamura, "Isolation, characterization and mapping of the mouse and human PRG4 (proteoglycan 4) genes," Cytogenetics and Cell Genetics, vol. 90, no. 3-4, pp. 291-297, 2000.

[161] B. L. Schumacher, J. A. Block, T. M. Schmid, M. B. Aydelotte, and K. E. Kuettner, "A novel proteoglycan synthesized and secreted by chondrocytes of the superficial zone of articular cartilage," Archives of Biochemistry and Biophysics, vol. 311, no. 1, pp. 144-152, 1994.

[162] G. D. Jay, D. E. Britt, and C.-J. Cha, "Lubricin is a product of megakaryocyte stimulating factor gene expression by human synovial fibroblasts," Journal of Rheumatology, vol. 27, no. 3, pp. 594-600, 2000.

[163] M. Taguchi, Y.-L. Sun, C. Zhao et al., "Lubricin surface modification improves extrasynovial tendon gliding in a canine model in vitro," Journal of Bone and Joint Surgery A, vol. 90, no. 1, pp. 129-135, 2008.

[164] Y. Sun, E. J. Berger, C. Zhao, G. D. Jay, K.-N. An, and P. C. Amadio, "Expression and mapping of lubricin in canine flexor tendon," Journal of Orthopaedic Research, vol. 24, no. 9, pp. 18611868, 2006.

[165] T. Funakoshi, T. Schmid, H.-P. Hsu, and M. Spector, "Lubricin distribution in the goat infraspinatus tendon: a basis for interfascicular lubrication," Journal of Bone and Joint Surgery A, vol. 90, no. 4, pp. 803-814, 2008.

[166] Y. L. Sun, C. Zhao, G. D. Jay, T. M. Schmid, K. N. An, and P. C. Amadio, "Effects of stress deprivation on lubricin synthesis and gliding of flexor tendons in a canine model in vivo," The Journal of Bone \& Joint Surgery, vol. 95, pp. 273-278, 2013.

[167] J. Braun, R. Van Den Berg, X. Baraliakos et al., "2010 update of the ASAS/EULAR recommendations for the management of ankylosing spondylitis," Annals of the Rheumatic Diseases, vol. 70, no. 6, pp. 896-904, 2011.

[168] R. Burgos-Vargas and J. C. Casasola-Vargas, "From retrospective analysis of patients with undifferentiated spondyloarthritis (SpA) to analysis of prospective cohorts and detection of axial and peripheral SpA," Journal of Rheumatology, vol. 37, no. 6, pp. 1091-1095, 2010.

[169] A. Malaviaya, "Classification of spondyloarthritis: a journey well worth," Indian Journal of Rheumatology, vol. 8, no. 3, pp. 122-129, 2013.

[170] D. D. O'Rielly DD and P. Rahman, "Advances in the genetics of spondyloarthritis and clinical implications," Current Rheumatology Reports, vol. 15, article 347, 2013.

[171] P. V. Balint, D. Kane, H. Wilson, I. B. McInnes, and R. D. Sturrock, "Ultrasonography of entheseal insertions in the lower limb in spondyloarthropathy," Annals of the Rheumatic Diseases, vol. 61, no. 10, pp. 905-910, 2002.

[172] P. Falsetti, B. Frediani, G. Filippou et al., "Enthesitis of proximal insertion of the deltoid in the course of seronegative spondyloarthritis: an atypical enthesitis that can mime impingement syndrome," Scandinavian Journal of Rheumatology, vol. 31, no. 3, pp. 158-162, 2002.

[173] D. McGonagle, H. Marzo-Ortega, P. O’Connor et al., "Histological assessment of the early enthesitis lesion in spondyloarthropathy," Annals of the Rheumatic Diseases, vol. 61, no. 6, pp. 534-537, 2002.

[174] R. Burgos-Vargas, "The assessment of the spondyloarthritis international society concept and criteria for the classification of axial spondyloarthritis and peripheral spondyloarthritis: a critical appraisal for the pediatric rheumatologist," Pediatric Rheumatology, vol. 10, article 14, 2012.

[175] L. S. Tam, J. Gu, and D. Yu, "Pathogenesis of ankylosing spondylitis," Nature Reviews Rheumatology, vol. 6, no. 7, pp. 399-405, 2010.

[176] P. C. Robinson and M. A. Brown, "The genetics of ankylosing spondylitis and axial spondyloarthritis," Rheumatic Disease Clinics of North America, vol. 38, pp. 539-553, 2012. 


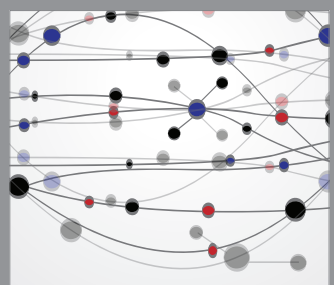

The Scientific World Journal
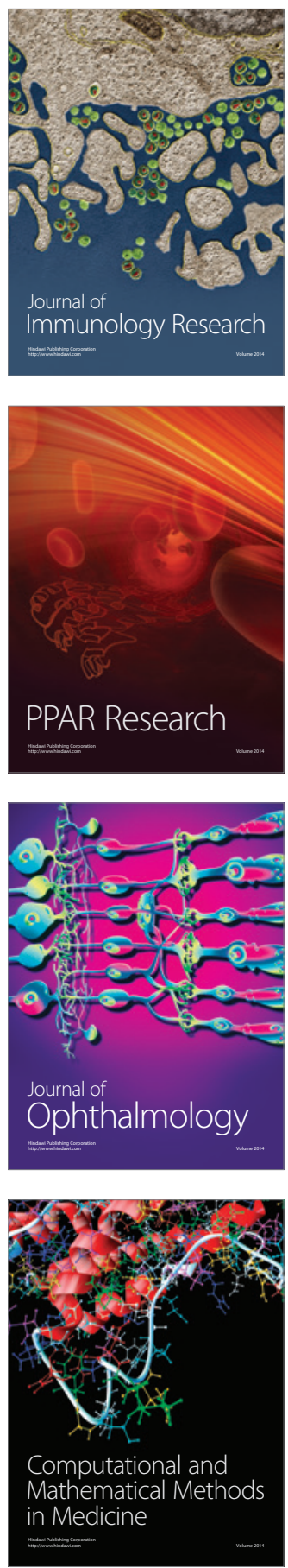

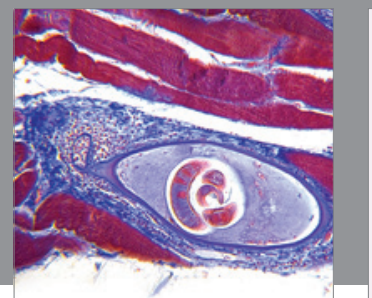

Gastroenterology

Research and Practice
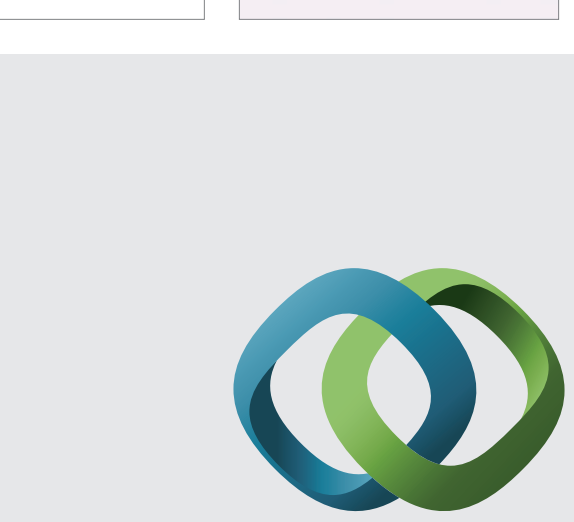

\section{Hindawi}

Submit your manuscripts at

http://www.hindawi.com
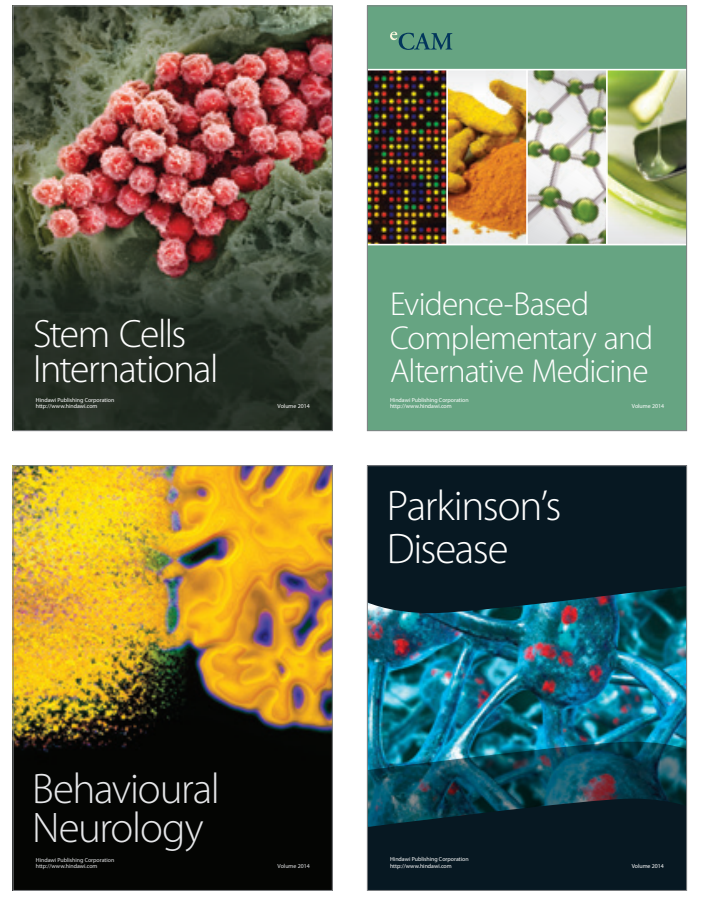
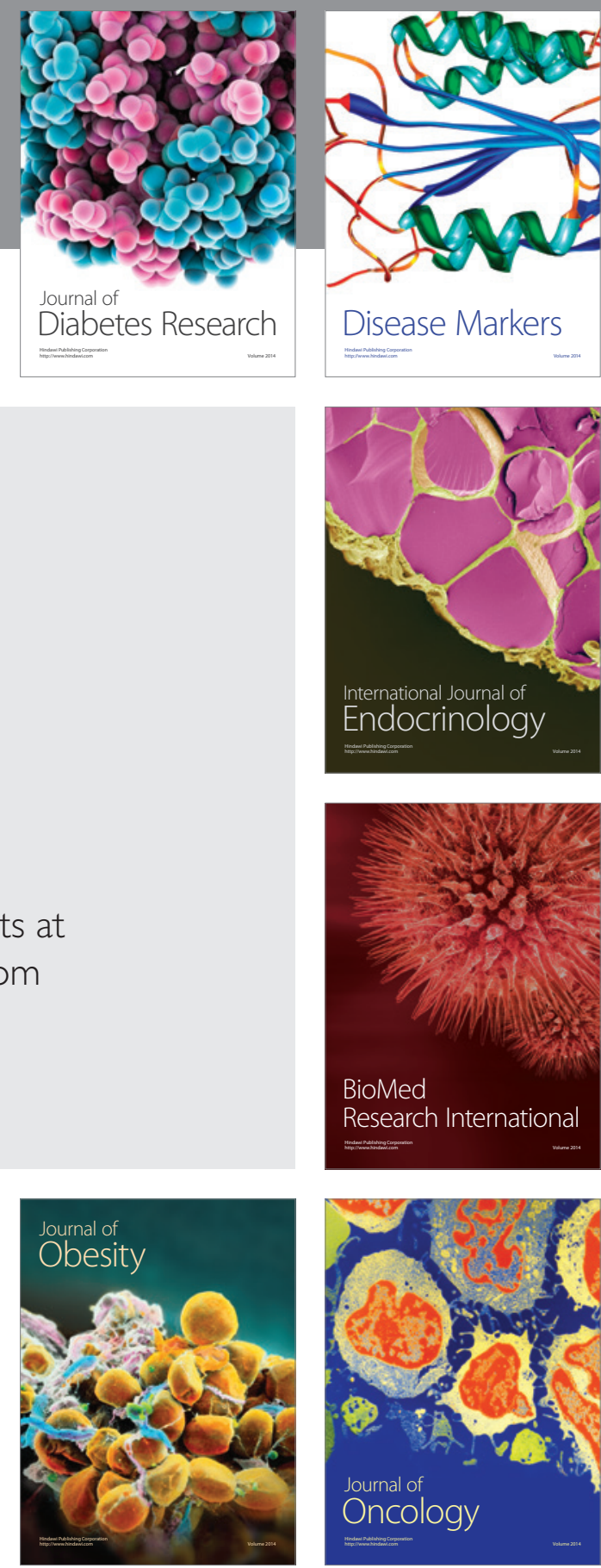

Disease Markers
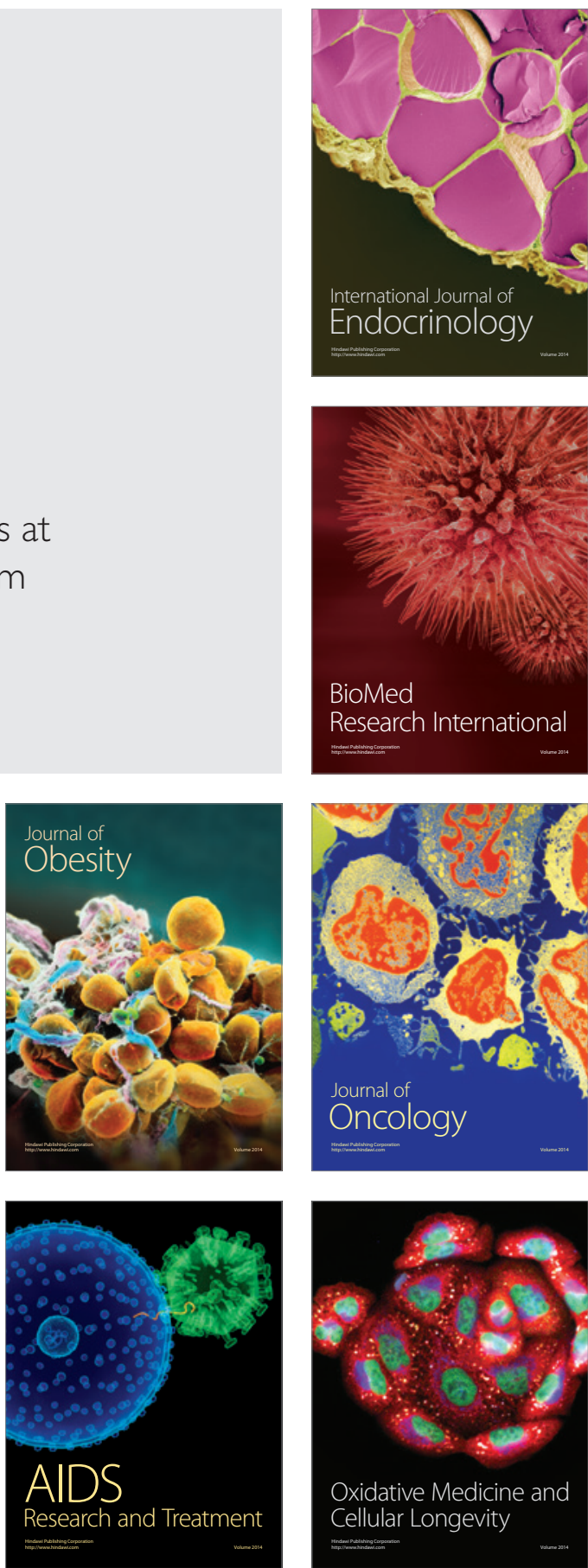